\title{
Ocular macrophage origin and heterogeneity during steady state and experimental choroidal neovascularization
}

\author{
Steven Droho', Benjamin R. Thomson², Hadijat M. Makinde ${ }^{3}$, Carla M. Cuda ${ }^{3}$, Harris Perlman³ and
} Jeremy A. Lavine ${ }^{1 *}$ (D)

\begin{abstract}
Background: Neovascular age-related macular degeneration (nAMD) commonly causes vision loss from aberrant angiogenesis, termed choroidal neovascularization (CNV). Macrophages are heterogeneous cells that are necessary for experimental CNV, present in human CNV samples, and can display diverse functions, which are dependent upon both their origin and tissue microenvironment. Despite these associations, choroidal macrophage heterogeneity remains unexplored.

Methods: We performed multi-parameter flow cytometry on wildtype (WT) and $\mathrm{Ccr}^{-1-}$ mice after laser injury to identify macrophage subtypes, and determine which subsets originate from classical monocytes. To fate map tissue resident macrophages at steady state and after laser injury, we used the $\mathrm{C} \times 3 \mathrm{Cr}^{\mathrm{CrEER} /+}$; Rosa26 $6^{25 G F P /+}$ mouse model. We reanalyzed previously published single-cell RNA-seq of human choroid samples from healthy and nAMD patients to investigate human macrophage heterogeneity, disease association, and function.

Results: We identified 4 macrophage subsets in mice: microglia, $\mathrm{MHCI}{ }^{+} \mathrm{CD} 11 \mathrm{c}^{-}, \mathrm{MHCI}{ }^{+} \mathrm{CD} 11 \mathrm{c}^{+}$, and $\mathrm{MHCII}^{-}$. Microglia are tissue resident macrophages at steady state and unaffected by laser injury. At steady state, $\mathrm{MHClI}^{-}$macrophages are long lived, tissue resident macrophages, while $\mathrm{MHCll}^{+} \mathrm{CD} 11 \mathrm{c}^{-}$and $\mathrm{MHCl}{ }^{+} \mathrm{CD} 11 \mathrm{c}^{+}$macrophages are partially replenished from blood monocytes. After laser injury, $\mathrm{MHCI}{ }^{+} \mathrm{CD} 11 \mathrm{c}^{-}$macrophages are entirely derived from classical monocytes, $\mathrm{MHCl}^{-}$macrophages originate from classical monocytes (90\%) and an expansion of tissue resident macrophages (10\%), and $\mathrm{MHCII}^{+} \mathrm{CD} 11 \mathrm{c}^{+}$macrophages are derived from classical monocytes (70\%), non-classical monocytes (10\%), and an expansion of tissue resident macrophages (20\%). Single-cell RNA-seq analysis of human choroid found 5 macrophage subsets: two $\mathrm{MHCll}^{+} \mathrm{CD} 11 \mathrm{C}^{-}$and three $\mathrm{MHCll}^{+} \mathrm{CD} 11 \mathrm{C}^{+}$populations. One $\mathrm{MHCl}^{+} \mathrm{CD} 11 \mathrm{C}^{+}$ subset was 78\% derived from a patient with nAMD. Differential expression analysis identified up-regulation of proangiogenic gene expression in one $\mathrm{MHCl}^{+} \mathrm{CD} 11 \mathrm{C}^{-}$and two $\mathrm{MHCl}^{+} \mathrm{CD} 11 \mathrm{C}^{+}$subsets, including the disease-associated cluster. The upregulated $\mathrm{MHCII}^{+} \mathrm{CD} 11 \mathrm{C}^{-}$pro-angiogenic genes were unique compared to the increased $\mathrm{MHCII}^{+} \mathrm{CD} 11 \mathrm{C}^{+}$ angiogenesis genes.

(Continued on next page)
\end{abstract}

\footnotetext{
* Correspondence: jeremy.lavine@northwestern.edu

${ }^{1}$ Department of Ophthalmology, Feinberg School of Medicine, Northwestern

University, 240 E Huron St, McGaw M343, Chicago, IL 60611, USA

Full list of author information is available at the end of the article
}

(c) The Author(s). 2020 Open Access This article is licensed under a Creative Commons Attribution 4.0 International License, which permits use, sharing, adaptation, distribution and reproduction in any medium or format, as long as you give appropriate credit to the original author(s) and the source, provide a link to the Creative Commons licence, and indicate if changes were made. The images or other third party material in this article are included in the article's Creative Commons licence, unless indicated otherwise in a credit line to the material. If material is not included in the article's Creative Commons licence and your intended use is not permitted by statutory regulation or exceeds the permitted use, you will need to obtain permission directly from the copyright holder. To view a copy of this licence, visit http://creativecommons.org/licenses/by/4.0/ The Creative Commons Public Domain Dedication waiver (http://creativecommons.org/publicdomain/zero/1.0/) applies to the data made available in this article, unless otherwise stated in a credit line to the data. 
(Continued from previous page)

Conclusions: Macrophage origin impacts heterogeneity at steady state and after laser injury in mice. Both mice and human patients demonstrate similar macrophage subtypes. Two discrete pro-angiogenic macrophage populations exist in the human choroid. Targeting specific, pro-angiogenic macrophage subsets is a potential novel therapeutic for nAMD.

Keywords: Age-related macular degeneration (AMD), Choroidal neovascularization (CNV), Angiogenesis, Macrophage

\section{Background}

Age-related macular degeneration (AMD) is the most common cause of vision loss in the developed world. AMD exists in two forms: non-neovascular/dry AMD and neovascular/wet AMD (nAMD). Non-neovascular AMD develops when inflammatory lipoprotein deposits called drusen accumulate under the retinal pigment epithelium (RPE). nAMD occurs when angiogenesis from the choroidal vasculature, theoretically trigged by drusen, invades through Bruch's membrane into the subRPE or sub-retinal space, a process termed choroidal neovascularization $(\mathrm{CNV})$. Current therapy for nAMD inhibits angiogenesis by blocking vascular endothelial growth factor (VEGF) via intravitreal injections, which improve vision by 5-10 letters [1]. However, frequent injections are expensive, include the risk of endophthalmitis, and $15 \%$ of patients lose vision despite monthly treatment [2]. Therefore, an unmet need exists for alternative therapies.

Multiple complement genes are genetically linked to AMD pathogenesis [3-5]. Drusen are comprised of several features, including complement factors and components [6], which are chemotactic for innate immune cells like macrophages [7]. Macrophages are detectable in surgically excised CNV membranes from patients [8], and loss of macrophages reduces experimental $\mathrm{CNV}$ area in mice [9]. Furthermore, macrophage depletion results in choroidal vascular atrophy in mice [10]. These data implicate macrophages in steady state vascular homeostasis and pathological angiogenesis during $\mathrm{CNV}$ and nAMD.

Macrophages are heterogeneous cells with distinct origins. Recent studies have identified macrophage populations derived from erythromyeloid progenitors (yolk sac, fetal liver) and bone marrow-derived peripheral blood monocytes [11]. In the central nervous system, specialized macrophage populations have been described including long-lived, yolk sac-derived microglia, and monocyte-derived choroid plexus macrophages [12]. Similarly, the eye contains distinct macrophage populations, including long-lived, yolk sac-derived retinal microglia, and blood monocyte-derived choroidal macrophages [13]. However, despite these similarities, far less is known about ocular macrophage heterogeneity and its impact upon function.
In this report, we investigated ocular macrophage heterogeneity, the origin of macrophage subsets, and their contribution to nAMD pathogenesis. Using multiparameter flow cytometry, we identified 4 macrophage subsets in mice: microglia, $\mathrm{MHCII}^{-}, \mathrm{MHCII}^{+} \mathrm{CD} 11 \mathrm{c}^{-}$, and $\mathrm{MHCII}^{+} \mathrm{CD} 11 \mathrm{c}^{+}$macrophages. Using the laserinduced $\mathrm{CNV}$ model, $\mathrm{C}-\mathrm{C}$ chemokine receptor 2 (CCR2) knockout mice, and fate mapping studies, we demonstrated that each macrophage subset has distinct origins. After laser injury, $\mathrm{MHCII}^{-}$macrophages originate from classical monocytes and an expansion of tissue resident macrophages, $\mathrm{MHCII}^{+} \mathrm{CD} 11 \mathrm{c}^{-}$macrophages are entirely derived from classical monocytes, and $\mathrm{MHCII}^{+} \mathrm{CD} 11 \mathrm{c}^{+}$ macrophages are derived from classical monocytes, nonclassical monocytes, and an expansion of tissue resident macrophages. At steady state, microglia and $\mathrm{MHCII}^{-}$ macrophages are long lived, tissue resident macrophages, while $\mathrm{MHCII}^{+}$macrophages are partially replenished from blood monocytes. In order to translate these findings to human, we re-analyzed recently published singlecell RNA-seq data from the human choroid [14]. Similar to our findings in mice, we identified choroidal macrophage subsets categorized based on MHCII and CD11C expression, including two $\mathrm{MHCII}^{+} \mathrm{CD} 11 \mathrm{C}^{-}$and three $\mathrm{MHCII}^{+} \mathrm{CD} 11 \mathrm{C}^{+}$populations. Gene ontology (GO) enrichment analysis found three subsets enriched for angiogenesis-related genes. These studies demonstrate the presence of macrophage heterogeneity in mice and humans, and support the concept of pro-angiogenic, pathogenic macrophages, which could be future therapeutic targets.

\section{Methods \\ Animals}

Breeding pairs of wildtype (C57BL6/J; \#000664), Ccr2 $2^{-/-}$ (B6.129S4-Ccr2 $2^{\text {tm1lff }} / \mathrm{J}$; 004999), Cx3cr1 ${ }^{\text {creER }}$ (B6.129P2(C)Cx3cr1 $1^{\text {tm2.1(cre/ERT2)Jung } / J ; ~ 020940), ~ a n d ~ R O S A 26 ~} 6^{\text {zSGFP }}$

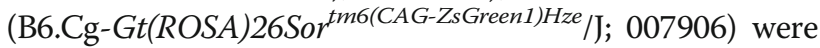
obtained from Jackson Labs (Bar Harbor, ME). Wildtype and $\mathrm{Crr}^{-/-}$animals used in this study were first- or second-generation crosses of parental mice. Mac ${ }^{\text {GFP }}$ $\left(\mathrm{C} \times 3 \mathrm{cr} 1^{\text {creER/+}} ; \mathrm{ROSA} 26^{z S G F P /+}\right)$ mice were first-generation offspring of the parental lines above resulting in mice heterozygous for each allele. One complete litter from each 
breeding pair was genotyped to confirm the correct genotype and the absence of the RD8 allele $\left(\mathrm{Crb1}^{-}\right)$. Genotyping services were performed by Transnetyx (Cordova, TN).

\section{Tamoxifen administration}

Tamoxifen (T5648, Sigma-Aldrich, St. Louis, MO) was dissolved in corn oil (C8267, Sigma-Aldrich) at $20 \mathrm{mg} /$ $\mathrm{ml}$ with shaking at $37^{\circ} \mathrm{C}$ overnight. Tamoxifen solutions were stored at $4{ }^{\circ} \mathrm{C}$ for less than 1 week. Tamoxifen was administered via intraperitoneal injection $(75 \mathrm{mg} / \mathrm{kg}$ body weight) twice separated by $48 \mathrm{~h}$ via a $25 \mathrm{G}$ needle. Control animals received $100 \mu$ of corn oil using the same technique. Tamoxifen or corn oil was administered at $6-8$ weeks of age.

\section{Laser-induced CNV}

Male and female 10-12-week-old mice were treated as previously described [15]. Briefly, mice were anesthetized with ketamine/xylazine (Akorn, Lake Forest, IL). Pain control and hydration were achieved with a $1 \mathrm{mg} / \mathrm{kg}$ subcutaneous injection of Meloxicam (Henry Schein Animal Health, Melville, NY). Eyes were anesthetized and dilated, and a cover slip was coupled to the cornea with Gonak (Akorn) for slit lamp biomicroscopy and laser. Four (immunofluorescence) or eight (flow cytometry, to increase inflammatory cell numbers) focal burns (75 $\mathrm{m}, 110 \mathrm{MW}, 100 \mathrm{~ms}$ ) were administered in each eye using a $532 \mathrm{~nm}$ argon ophthalmic laser (IRIDEX, Mountain View, CA) via a slit lamp (Zeiss, Oberkochen, Germany).

\section{Immunofluorescence}

Eyes were treated as previously described [15]. Briefly, mice were sacrificed 3 days (IBA1 and ICAM-2) or 2 weeks (ICAM-2) after laser-induced CNV. Enucleated eyes were fixed for $1 \mathrm{~h}$ in $1 \%$ paraformaldehyde (\#15713S, Electron Microscopy Sciences, Hatfield, PA) at room temperature. Eyes were washed in PBS and dissected to remove conjunctiva, cornea, iris, ciliary body, lens, and retina leaving a posterior eye cup of RPE, choroid, and sclera. Eye cups were blocked in Tris-buffered saline (TBS) $+5 \%$ Donkey serum (S30, Sigma-Aldrich), then treated with an anti-IBA1 and/or anti-ICAM-2 primary antibody (both 1:500, Table 1), and Alexa Fluor 647conjugated anti-rabbit and/or Alexa Fluor 488conjugated anti-rat secondary antibody (Table 1). Pictures were captured on a Ti2 widefield microscope (Nikon, Melville, NY). Area was analyzed using ImageJ after masking of images.

\section{Flow cytometry of whole eyes}

Experiments were performed as described [16]. Briefly, mice were sacrificed and eyes enucleated into HBSS.
Animals were not perfused as we previously demonstrated no difference in macrophage numbers at steady state or after laser injury with or without systemic perfusion [16]. Eyes were cleaned of optic nerve, extraocular muscles, orbital tissue, and conjunctiva. Whole mouse eyes including cornea, sclera, iris, ciliary body, vitreous, retina, and choroid, were minced into small pieces. Eye pieces were further mechanically and chemically digested before passing through a fine mesh filter to obtain a single cell suspension. Cell suspensions were stained for live cells and washed. Cell suspensions were blocked and stained with cell surface antibodies found in Table 1. Both eyes were pooled from one mouse to determine cells per mouse, using counts beads as previously described [16]. For dissected iris, choroid, and retina, only chemical digestion was performed without mincing of tissue or mechanical digestion. After passing the tissue through a fine mesh filter, the dissected and whole eye specimens were treated identically. Two unlasered mice in tamoxifen studies were pooled to increase macrophage numbers at steady state. Samples were run on a modified LSRII (BD Biosciences, San Jose, CA) and analyzed using FlowJo v10.

\section{Flow cytometry of peripheral blood}

Blood from sacrificed male animals was obtained with a 30G heparin needle via cardiac puncture. Samples were placed in EDTA tubes (Sarstedt, Numbrecht, Germany) to prevent clotting. In $5 \mathrm{ml}$ polystyrene tubes, $1 \mu \mathrm{l}$ of $\mathrm{F}_{\mathrm{c}}$ block was incubated with $90 \mu \mathrm{l}$ of blood for $15 \mathrm{~min}$ at room temperature. To this mixture, $10 \mu \mathrm{l}$ of an antibody cocktail (Table 1) was added. Samples were vortexed gently and incubated for $30 \mathrm{~min}$ at $4{ }^{\circ} \mathrm{C}$. Following incubation, $1.5 \mathrm{ml}$ of lysis and fixation buffer (FACSLyse, BD Biosciences) was added. Samples were vortexed gently and placed for $10 \mathrm{~min}$ in the dark. Following lysis, $2 \mathrm{ml}$ of MACS buffer (Miltenyi Biotec, Auburn, CA) stopped the reaction. Samples were centrifuged at $350 \times g$ at $4{ }^{\circ} \mathrm{C}$ for $10 \mathrm{~min}$. Pellets were resuspended in $500 \mu \mathrm{l}$ MACS buffer and moved to $1.2 \mathrm{ml}$ polypropylene tubes. This wash was repeated 3 times before resuspending in a final volume of $150 \mu \mathrm{l}$ MACS buffer. Samples were run on a modified LSRII and analyzed using FlowJo v10.

\section{Bioinformatics}

Gene expression data (.tsv files) from human choroidal samples were downloaded from the GEO database (GSE135922). Data was imported into Seurat v3 [17, 18]. The FindIntegrationAnchors followed by the IntegrateData functions (dims 1:50) were used to integrate the data into one data set and perform batch corrections. The data were rescaled (ScaleData function), and principal component analysis (PCA) was performed (RunPCA, npcs $=50)$. The Elbow Plot technique was used to 
Table 1 Antibodies used in this study

\begin{tabular}{|c|c|c|c|c|}
\hline Antibody & Fluorophore & Clone & Usage & Manufacturer \\
\hline Rat anti-mouse CD16/CD32 & N/A & $2.4 \mathrm{G} 2$ & $F_{c}$ block & BD Biosciences \\
\hline Mouse anti-mouse CD64 & PE & $\times 54-5 / 7.1$ & Eye & BioLegend \\
\hline Hamster anti-mouse CD11c & BV 421 & HL3 & Eye $^{a}$ & BD Biosciences \\
\hline Rat anti-mouse Ly6G & PE-CF594 & $1 \mathrm{~A} 8$ & Eye & BD Biosciences \\
\hline Mouse anti-mouse NK1.1 & PE-CF594 & PK136 & Eye & BD Biosciences \\
\hline Rat anti-mouse Siglec F & PE-CF594 & E50-2440 & Eye & BD Biosciences \\
\hline Rat anti-mouse B220 & PE-CF594 & RA3-6B2 & Eye & BD Biosciences \\
\hline Rat anti-mouse CD8 & PE-CF594 & $53-6.7$ & Eye and blood & BD Biosciences \\
\hline Rat anti-mouse CD4 & PE-CF594 & RM4-5 & Eye and blood ${ }^{a}$ & BD Biosciences \\
\hline Rat anti-mouse MHC ॥ & AlexaFluor 700 & M5/114.15.2 & Eye & BioLegend \\
\hline Rat anti-mouse CD11b & APC-Cy7 & $\mathrm{M} 1 / 70$ & Eye $^{a}$ & BD Biosciences \\
\hline Rat anti-mouse CD45 & PE-Cy7 & 30-F11 & Eye and blood ${ }^{a}$ & BD Biosciences \\
\hline Rat anti-mouse Ly6G & PerCP-Cy5.5 & $1 \mathrm{~A} 8$ & Blood $^{a}$ & BD Biosciences \\
\hline Rat anti-mouse CD11b & eFluor 450 & $\mathrm{M} 1 / 70$ & Blood $^{a}$ & Invitrogen \\
\hline Rat anti-mouse CD19 & APC & $1 \mathrm{D} 3$ & Blood $^{a}$ & BD Biosciences \\
\hline Mouse anti-mouse NK1.1 & AlexaFluor 700 & PK136 & Blood & BD Biosciences \\
\hline Rat anti-mouse CD115 & PE & AFS98 & Blood & Invitrogen \\
\hline Rat anti-mouse CD19 & PE & 1D3 & Compensation & BD Biosciences \\
\hline Rat anti-mouse CD19 & AlexaFluor 700 & 1D3 & Compensation & BD Biosciences \\
\hline Fixable viability dye & eFluor 506 & N/A & Eye $^{a}$ & Invitrogen \\
\hline Rat anti-mouse CD102 (ICAM2) & N/A & $3 \mathrm{C} 4(\mathrm{mlC} 2 / 4)$ & Immunofluorescence & BD Biosciences \\
\hline Rabbit anti-mouse IBA1 & N/A & 019-19741 & Immunofluorescence & Wako \\
\hline Donkey anti-rat $(\mathrm{H}+\mathrm{L})$ & AlexaFluor 488 & N/A & Immunofluorescence & Invitrogen \\
\hline Donkey anti-rabbit $(\mathrm{H}+\mathrm{L})$ & AlexaFluor 647 & N/A & Immunofluorescence & Invitrogen \\
\hline
\end{tabular}

List of antibodies, fluorophores, manufacturers, and clones. ${ }^{a}$ Antibody also used for compensation setup

identify 19 significant principal components (PCs). Cells were clustered using FindNeighbors (dims $=1: 19$ ) followed by FindClusters (resolution $=0.4$ ). The RunUMAP function was used to visualize the cell clusters. Differential expression and cell identification were performed using FindAllMarkers (min.pct $=0.25$, logfc.threshold $=0.25$ ). The DotPlot function was used to visualize gene expression.

The leukocyte subset was created by making a subset of the leukocyte clusters, followed by scaling the data (ScaleData), and PCA analysis (RunPCA). The Elbow Plot technique was again used to identify 12 significant PCs. The cells were clustered using FindNeighbors $(\operatorname{dims}=1: 12$ ) followed by FindClusters (resolution $=0.4$ ). Clusters were visualized using RunUMAP. Differential expression and cell identification were again performed using FindAllMarkers (min.pct $=0.25$, logfc.threshold $=\log (2)$ ). The DotPlot function was used to visualize gene expression. Enrichment in nAMD patients was performed by DimPlot (group.by=orig.ident) and table(eye.integrated@active.ident, eye.integrated\$orig.ident). Gene expression was visualized using the VlnPlot function.
Gene ontology (GO) enrichment analysis was performed on upregulated and downregulated genes independently using a fold change cut-off $=>2.0$ or $<0.5$, and adjusted $p$ value $<0.001$. GOrilla was used for GO enrichment [19, 20], using a background of genes expressed only in MacA, Mac-B, Mac-C, Mac-D, and Mac-E. REVIGO was used to remove dispensable GO terms [21]. All GO terms are visualized in Fig. 7 that met a dispensability cutoff of $<$ 0.05 , enrichment $>5$-fold, number of genes (b) $>2$, and false discovery rate (FDR) $q$ value $<0.05$.

\section{Statistical analysis}

Comparisons for CNV area were made by Mann-Whitney test due to non-parametric data distribution. Flow cytometry comparisons of macrophage numbers were made using the Brown-Forsythe and Welch ANOVA followed by Dunnett's T3 multiple comparison test due to unequal variances between unlasered and lasered mice.

\section{Results}

We used the experimental murine laser-induced CNV model to investigate macrophage heterogeneity in 
angiogenesis. This model triggers robust mononuclear phagocyte infiltration $\left(\mathrm{IBA}^{+}\right.$cells, Fig $1 \mathrm{a}, \mathrm{c}$ ) with minimal neovascularization (ICAM2, Fig. 1b, c) on day 3. The angiogenic phase with many ICAM2 ${ }^{+}$neovessels is standardly characterized on days 7-14 (Fig. 2a). We treated 10-12-week-old male and female mice with laser and performed multi-parameter flow cytometry on day 3, 5, and 7 post laser (Fig. 1d). We dissected whole eyes and removed conjunctiva, extraocular muscles, orbital tissue, and optic nerve. Our digestion included cornea, sclera, iris, ciliary body, vitreous, retina, and choroid in order to achieve maximal rigor and reproducibility while minimizing variance created by unequal dissections. On day 3 after laser injury, we gated singlets, excluded dead cells and count beads, and selected $\mathrm{CD} 45^{+}, \mathrm{CD} 11 \mathrm{~b}^{+}$, Lineage $^{-}$(Lin: CD4, CD8, B220, NK1.1, SiglecF, Ly6G) cells (Fig. 1e). We used CD45 expression levels to differentiate microglia $\left(C D 45^{\mathrm{dim}}\right)$ [22] from infiltrating immune cells $\left(C D 45^{\text {high }}\right.$, Fig. 1f, j). We identified microglia as $\mathrm{CD}_{6} 4^{+} \mathrm{MHCII}^{\text {low }}$ in the $\mathrm{CD} 45^{\mathrm{dim}}$ population (Fig. $1 \mathrm{~h}$, 1). We delineated three infiltrating macrophage populations in the $\mathrm{CD} 45^{\text {high }}$ population: $\mathrm{MHCII}^{-}$, $\mathrm{MHCII}^{+} \mathrm{CD} 11 \mathrm{c}^{-}$, and $\mathrm{MHCII}^{+} \mathrm{CD} 11 \mathrm{c}^{+}$macrophage subsets (Fig. 1g, i, k, m). Fluorescence minus one controls for this flow cytometry panel were previously published [16].

The $\mathrm{Cr} 2^{-/-}$mouse demonstrates deficient recruitment and mobilization of classical monocytes, and demonstrates reduced laser-induced $\mathrm{CNV}$ area [23], suggesting that classical monocyte-derived macrophages stimulate angiogenesis in the eye after laser injury. We used the $\mathrm{Ccr} 2^{-/-}$ mouse model to investigate the influence of macrophage origin on each macrophage subtype. We first independently corroborated that female $\mathrm{Ccr} 2^{-/-}$mice demonstrate reduced $\mathrm{CNV}$ area at day 14 (Fig. 2a, b). Alternatively, male $\mathrm{Cr}^{-/-}$mice showed no difference in $\mathrm{CNV}$ area compared to wildtype (WT) male mice on day 14 (Fig. 2c). Based upon these sex differences and the increased prevalence of nAMD in female patients [24, 25], we thoroughly investigated the number of macrophages after laser injury in male and female WT and $\mathrm{Ccr} 2^{-/-}$mice. We found that the $\mathrm{CD} 45^{\mathrm{dim}} \mathrm{CD} 64^{+}$putative microglia, which are yolk sacderived, long-lived, and self-replenishing retinal macrophages, were unchanged by laser in both genotypes and sexes, as expected (Fig. 2d, e). In contrast, $\mathrm{MHCII}^{-}$macrophage numbers peaked with a 14.6-fold increase in female WT mice on day 3 ( $p<0.01$, Fig. 2f, g). In $C c r 2^{-/-}$female mice, $\mathrm{MHCII}^{-}$macrophage numbers increased from 257 \pm 31 cells per mouse to $525 \pm 67$ cells per mouse (2.0-fold, $p<0.05$ vs. day 0 ), which was significantly reduced compared to WT female mice on day $3(p<0.05$, Fig. $2 \mathrm{f}, \mathrm{g})$. $\mathrm{MHCII}^{-}$macrophages were equally increased in female WT and $C c r 2^{-/-}$mice on day 5 ( $p<0.05$ for both genotypes vs. day 0), and back to baseline on day 7 (Fig. 2f, g).
In male WT mice, $\mathrm{MHCII}^{-}$macrophage numbers rose 14.8 -fold on day 3 ( $p<0.05$ vs. day 0 ), while $C c r 2^{-/-}$male mice demonstrated a 2.3-fold increase on day $3(p<0.05$ vs. day 0 ), which was significantly reduced compared to WT mice ( $p<0.05$ between groups, Fig. $2 \mathrm{~h}$ ). On day 7 , male WT mice displayed a 3.7 -fold elevation $(p<0.001$ vs. day 0 ), male $\mathrm{Ccr}^{-1-}$ mice showed a 2.0-fold increase ( $p<$ 0.01 vs. day 0 ), and this was significantly different between groups $(p<0.05$, Fig. $2 \mathrm{~h})$.

Similar to $\mathrm{MHCII}^{-}$macrophages, $\mathrm{MHCII}^{+} \mathrm{CD} 11 \mathrm{c}^{+}$macrophages peaked with a 12.7-fold increase on day $3(p<0.01$, Fig. 3a, d) and a 4.3-fold elevation on day $5(p<0.05)$ in female WT mice. In $\mathrm{Ccr} 2^{-/-}$female mice, $\mathrm{MHCII}^{+} \mathrm{CD} 11 \mathrm{c}^{+}$ macrophage numbers increased from $120 \pm 27$ to $521 \pm 83$ cells per mouse ( 4.3 -fold, $p<0.05$ vs. day 0 ), which was significantly decreased compared to female WT mice on day 3 $(p<0.01$, Fig. 3a, d). Male WT mice demonstrated a 7.6-fold increase on day $3(p<0.001$, Fig. 3e) and a 4.3-fold upregulation of $\mathrm{MHCII}^{+} \mathrm{CD} 11 \mathrm{c}^{+}$macrophages on day $7(p<0.05$, Fig. $3 \mathrm{e})$. In $\mathrm{Ccr} 2^{-/-}$male mice, $\mathrm{MHCII}^{+} \mathrm{CD} 11 \mathrm{c}^{+}$macrophages enlarged by 2.5 -fold on day 3 only ( $p<0.05$, Fig. 3e), displaying significant reductions compared to WT on day 3 and day 7 ( $p<0.05$ between genotypes, Fig. 3e).

$\mathrm{MHCII}^{+} \mathrm{CD} 11 \mathrm{c}^{-}$macrophages increased 9.6-fold $(p<$ 0.01 vs. day 0$)$ on day 3 and 5.3 -fold $(p<0.01$ vs. day 0$)$ on day 5 in female WT mice, and were completely unchanged in $\mathrm{Crr}^{-/-}$female mice (Fig. 3a, b). In male mice, $\mathrm{MHCII}^{+} \mathrm{CD} 11 \mathrm{c}^{-}$macrophages numbers elevated 5.8 -fold ( $p<0.001$ vs. day 0$)$ on day 3 and 2.7 -fold $(p<$ 0.01 vs. day 0 ) on day 7 , and were completely unchanged in $\mathrm{Ccr}^{-/-}$male mice (Fig. 3c). These results suggest that the increase in $\mathrm{MHCII}^{+} \mathrm{CD} 11 \mathrm{c}^{-}$macrophages with laser is entirely derived from classical monocytes. Alternatively, the laser injury-induced elevation of $\mathrm{MHCII}^{-}$and $\mathrm{MHCII}^{+} \mathrm{CD} 11 \mathrm{c}^{+}$macrophages is primarily driven by classical monocytes, but there are additional contributions from non-classical monocytes and/or tissue resident macrophages in male and female mice.

In order to investigate tissue resident macrophages, we generated $\mathrm{Cx} 3 \mathrm{Crl}^{\mathrm{CreER} /+}$; Rosa26 $6^{z S G F P /+}$ mice (Mac ${ }^{\mathrm{GFP}}$, Fig. 4a). Upon tamoxifen administration, Cre expression in $\mathrm{C} x 3 \mathrm{cr} 1^{+}$cells will excise the stop codon prior to the zsGreen gene, causing irreversible bright zsGFP expression for fate mapping [26]. Mac ${ }^{\mathrm{GFP}}$ mice underwent intraperitoneal tamoxifen administration at 6 weeks of age. This strategy labeled $\mathrm{C} \times 3 \mathrm{cr} 1^{+}$tissue resident macrophages and peripheral blood monocytes as $\mathrm{GFP}^{+}$. Peripheral blood monocytes are replenished from bone marrow after $\sim 2$ weeks; thus, $\sim 4$ weeks after tamoxifen administration, we expect peripheral blood monocytes to be $\mathrm{GFP}^{-}$. We performed multi-parameter flow cytometry on peripheral blood. One week after tamoxifen administration, peripheral blood monocytes $(72.3 \%$, Fig. S1E), NK cells (18.2\%, Fig. S1F), and neutrophils (0.37\%, Fig. 


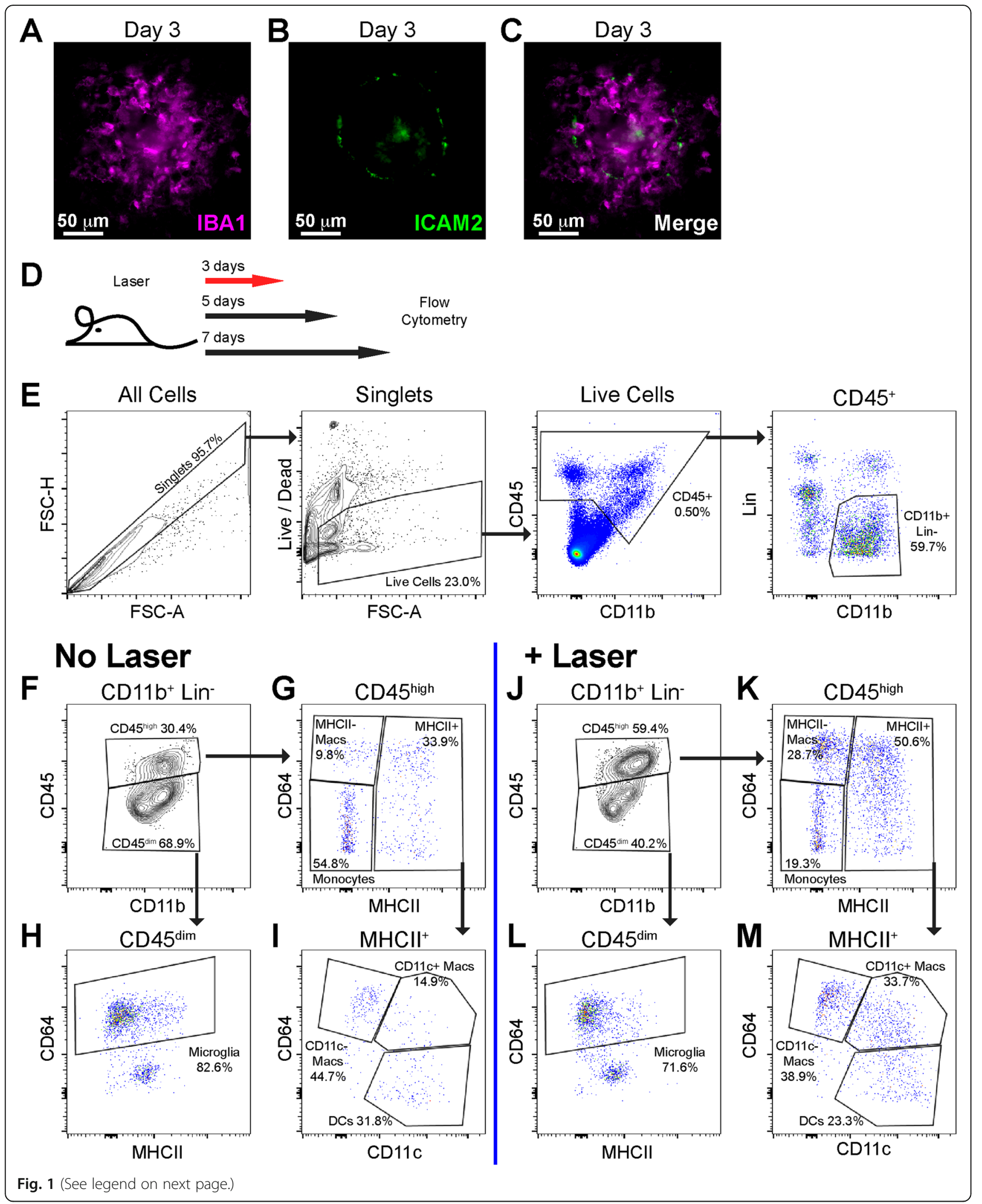


(See figure on previous page.)

Fig. 1 Laser CNV model and flow cytometry gating strategy for mononuclear phagocytes. IBA1 (a), ICAM-2 (b), and merged (c) images of a flat-mounted choroidal lesion on day 3. $\mathbf{d}$ Schematic of experimental design. Red arrow indicates that the representative plots in $\mathbf{e}$, and $\mathbf{j}-\mathbf{m}$ are from day 3 after laser injury. e Initial gating strategy demonstrating identification of singlet cells (left), delineation of live cells with removal of debris and count beads (middle left), gating of $\mathrm{CD}_{5}{ }^{+}$cells (middle right), and selection of CD11 b ${ }^{+}$, Lin cells (Lin $=C D 4, C D 8, B 220, N K 1.1$, SiglecF, Ly6G). $\mathbf{f}-\mathbf{m}$ Gating strategy for identification of monocytes, dendritic cells (DCs), microglia, $\mathrm{MHCll}^{-}, \mathrm{MHCII}^{+} \mathrm{CD} 11 \mathrm{c}^{-}$, and $\mathrm{MHCl}{ }^{+} \mathrm{CD} 11 \mathrm{c}^{+}$macrophages from unlasered $(\mathbf{f}-\mathbf{i})$ and laser treated $(\mathbf{j}-\mathbf{m})$ mice. $\mathbf{f}, \mathbf{j}$ Separation of

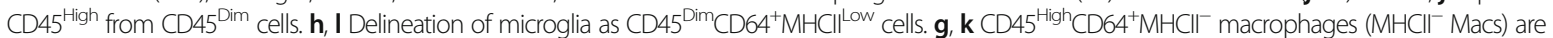
increased with laser. i, $\mathbf{m}$ Increased $\mathrm{CD} 45^{\text {High }} \mathrm{CD} 64^{+} \mathrm{MHCl}{ }^{+} \mathrm{CD} 11 \mathrm{c}^{-}\left(\mathrm{CD} 11 \mathrm{c}^{-}\right.$Macs) and $\mathrm{CD} 45^{\text {High }} \mathrm{CD} 64^{+} \mathrm{MHCl}{ }^{+} \mathrm{CD} 11 \mathrm{c}^{+}$macrophages $\left(\mathrm{CD} 11 \mathrm{c}^{+}\right.$Macs) with laser treatment

S1I) demonstrated increased percentages of $\mathrm{GFP}^{+}$cells compared to corn oil vehicle controls. At 4-6 weeks post-tamoxifen treatment, monocytes and all other cell types had equivalent $\mathrm{GFP}^{+}$percentages compared to control mice (Fig. S1E-J). These data confirmed that the Mac ${ }^{\mathrm{GFP}}$ mouse is an effective fate mapping model for tissue resident macrophages.

Using our Mac ${ }^{\mathrm{GFP}}$ fate mapping model, we subjected male and female mice to tamoxifen administration at 6 weeks of age followed by laser treatment at 10-12 weeks of age (Fig. 4b). We performed multi-parameter flow cytometry on day 3 after laser injury, the peak of macrophage recruitment, in order to determine the contribution of tissue resident $\left(\mathrm{GFP}^{+}\right)$vs. monocytederived $\left(\mathrm{GFP}^{-}\right)$macrophages to each macrophage subset. The number of $\mathrm{GFP}^{+}$microglia increased with tamoxifen compared to corn oil control in female (Fig. $4 \mathrm{~d}, p<$ $0.06)$ and male (Fig. 4h, $p<0.01$ ) mice. Similarly, the number of $\mathrm{GFP}^{-}$microglia decreased with tamoxifen treatment in female (Fig. 4d, $p<0.06$ ) and male (Fig. 4h, $p<0.01$ ) mice. After laser injury, there was no change in $\mathrm{GFP}^{+}$microglia in male or female mice (Fig. 4d, h), which was expected because laser injury of the choroid should not significantly affect retinal microglia numbers. Alternatively, $\mathrm{GFP}^{+} \mathrm{MHCII}^{-}$macrophages increased from $49 \pm 11$ cells per mouse in the control to $96 \pm 10$ cells per mouse with tamoxifen (Fig. 4e, $p<0.05$ ) and $490 \pm$ 109 cells per mouse with tamoxifen + laser (Fig. 4e, $p<$ 0.05 vs. tamoxifen) in female mice. This effect size ( 400 cells) is equivalent to the increased number of macrophages observed in lasered $\mathrm{Cr} 2^{-/-}$female mice on day 3 (Fig. 2g). $\mathrm{GFP}^{-} \mathrm{MHCII}^{-}$macrophages were dramatically upregulated from $<100 \pm 6-11$ cells per mouse in control and tamoxifen-treated mice to $4847 \pm 1805$ cells per mouse in tamoxifen + laser-treated mice (Fig. $4 \mathrm{e}, p$ $<0.09$ ). Nearly identical findings were observed in male mice. $\mathrm{GFP}^{+} \mathrm{MHCII}^{-}$macrophages increased from $26 \pm 1$ in control male eyes to $48 \pm 5$ cells per mouse with tamoxifen (Fig. 4i, $p<0.05$ ) and $428 \pm 93$ cells per mouse in laser + tamoxifen-treated mice (Fig. 4i, $p<0.05$ ). The increased $\mathrm{GFP}^{+} \mathrm{MHCII}^{-}$macrophage numbers were very similar to lasered $\mathrm{Cr} 2^{-1-}$ male mice, which increased from $169 \pm 30$ cells per mouse on day 0 to $397 \pm 59$ cells per mouse on day 3 (Fig. $2 \mathrm{~h}, p<0.05$ ), suggesting that increased $\mathrm{MHCII}^{-}$macrophage numbers with laser are mainly due to classical monocyte recruitment with a minor contribution from expanded tissue resident macrophages.

We next investigated the two $\mathrm{MHCII}^{+}$macrophages subsets. The number of $\mathrm{GFP}^{+} \mathrm{MHCII}^{+} \mathrm{CD} 11 \mathrm{c}^{-}$macrophages increased with tamoxifen treatment (Fig. 4f, $p<$ 0.05 ) but were unchanged with laser injury. Alternatively, $\mathrm{GFP}^{-} \mathrm{MHCII}{ }^{+} \mathrm{CD} 11 \mathrm{c}^{-}$macrophages increased from $50-80 \pm 8-15$ cells per mouse in unlasered mice to $1599 \pm 252$ cells per mouse after laser injury (Fig. 4f, $p<0.01)$. Similar results were observed in male mice (Fig. 4j), confirming that all $\mathrm{MHCII}^{+} \mathrm{CD} 11 \mathrm{c}^{-}$macrophages are classical monocyte-derived macrophages after laser injury.

The number of $\mathrm{GFP}^{+} \mathrm{MHCII}^{+} \mathrm{CD} 11 \mathrm{c}^{+}$macrophages increased from $22 \pm 6$ cells per mouse in control to $46 \pm 5$ cells per mouse with tamoxifen treatment (Fig. 4g, $p<$ $0.06)$ and $121 \pm 22$ cells per mouse with laser + tamoxifen treatment (Fig. 4g, $p<0.05$ ) in female mice. The increased number of $\mathrm{GFP}^{+} \mathrm{MHCII}{ }^{+} \mathrm{CD} 11 \mathrm{c}^{+}$macrophages was less than $\mathrm{Ccr}^{-/-}$female mice $(120 \pm 27$ to $521 \pm 83$ cells per mouse, Fig. 3d). In male mice, $\mathrm{GFP}^{+} \mathrm{MHCII}{ }^{+} \mathrm{CD} 11 \mathrm{c}^{+}$ macrophage numbers expanded from $14 \pm 4$ in control to $38 \pm 5$ with tamoxifen (Fig. $4 \mathrm{k}, p<0.05$ ) and $115 \pm 24$ cells per mouse with tamoxifen and laser (Fig. $4 \mathrm{k}, p<$ 0.07). Again, this effect size was reduced compared to $\mathrm{Ccr}^{-1-}$ male mice $(136 \pm 20$ to $335 \pm 48$, Fig. 3e). These data suggest that increased $\mathrm{MHCII}^{+} \mathrm{CD} 11 \mathrm{c}^{+}$macrophages with laser injury originate from classical monocyte infiltration, tissue resident macrophage expansion, and a third source, which we suspect is the non-classical monocyte population.

To better understand ocular macrophages at steady state, we dissected eyes into iris, retina, and choroid fractions to determine the contribution from each tissue to each macrophage subset using multi-parameter flow cytometry. $\mathrm{MHCII}^{-}$macrophages were most abundant overall, and were distributed $80 \%$ in the iris and $20 \%$ in the choroid (Fig. 5a, d). $\mathrm{MHCII}^{+} \mathrm{CD} 11 \mathrm{c}^{-}$macrophages were similarly divided $70 \%$ iris and 30\% choroid (Fig. 5b, d). $\mathrm{MHCII}^{+} \mathrm{CD} 11 \mathrm{c}^{+}$macrophages were allocated $60 \%$ iris, $35 \%$ choroid, and $5 \%$ retina (Fig. 5 c, d). The retina was almost entirely microglia, and the choroid contained 52\% 


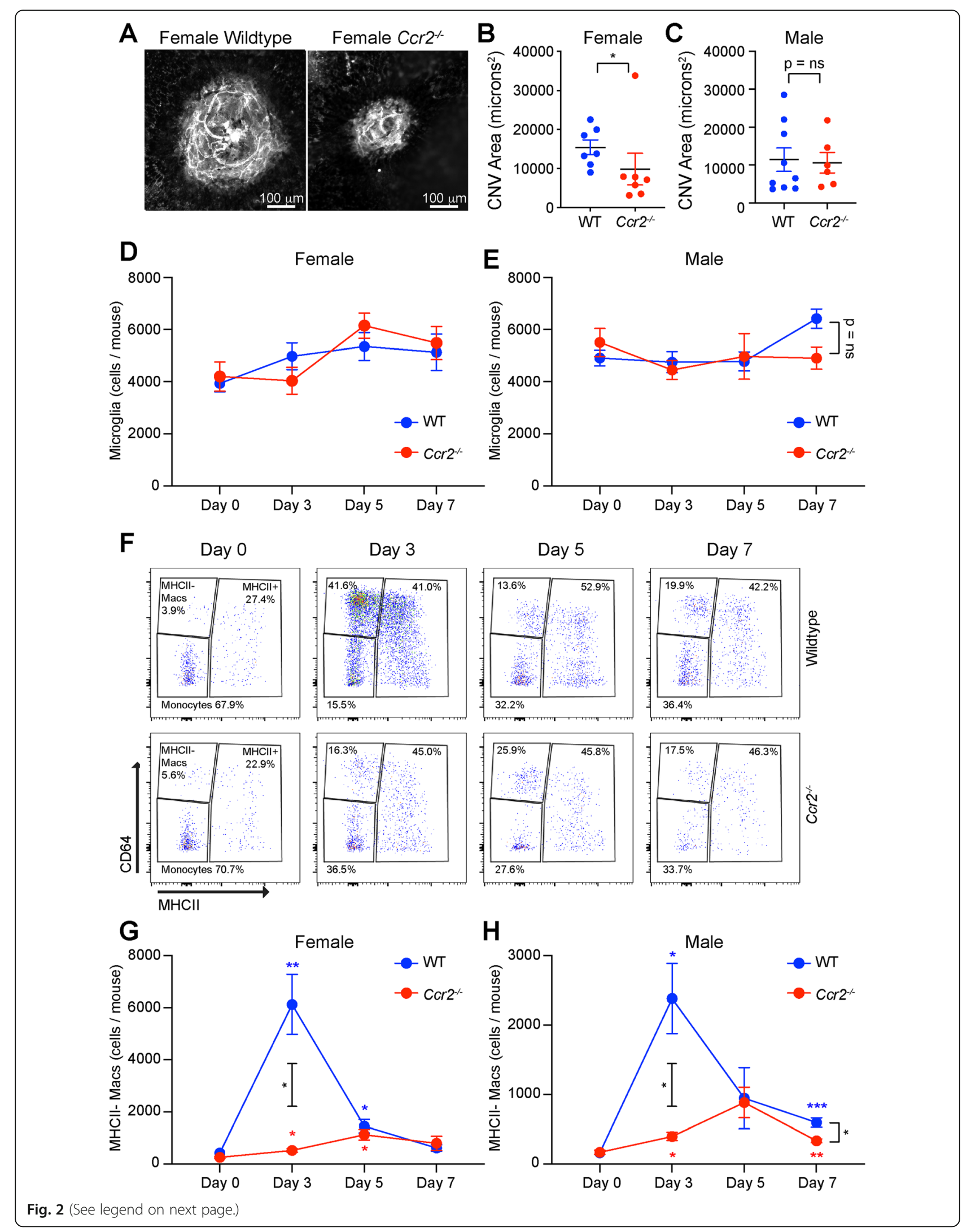


(See figure on previous page.)

Fig. 2 Reduced MHCII- macrophage numbers in $\mathrm{CCr}^{-/-}$mice after laser injury. Representative ICAM2 immunofluorescence imaging (a) and quantitative analysis of CNV area for female (b) and male (c) wildtype (WT) vs. C Cr2 ${ }^{-1-}$ mice. Microglia numbers were not changed by laser or genotype in female (d) or male (e) mice. $\mathbf{f}$ Representative flow cytometry pseudocolor plots from wildtype and $\mathrm{Ccr} 2^{-1-}$ female mice from day 0 , day 3, day 5, and day 7. $\mathrm{MHCII}^{-}$macrophage numbers peaked in WT mice on day 3 and were blunted in $\mathrm{Ccr} 2^{-1-}$ female $(\mathbf{g})$ and male $(\mathbf{h})$ mice. ${ }^{*} p$ $<0.05 ;{ }^{* *} p<0.01 ;{ }^{* * *} p<0.001$. Colored asterisk = significant difference from day 0 within genotype (blue $=\mathrm{WT}$, red $=\mathrm{Ccr} 2^{-/-}$mice). Black asterisk = significant difference between genotypes on day 3 or day 7. $N=8-11$ per group in both male and female mice. CNV was compared using the Mann-Whitney test $(\mathbf{b}, \mathbf{c})$. Macrophage numbers were compared using the Brown-Forsythe and Welch ANOVA followed by Dunnett's T3 multiple comparison (d, e, $\mathbf{g}, \mathbf{h})$

$\mathrm{MHCII}^{-}, 32 \% \mathrm{MHCII}^{+} \mathrm{CD} 11 \mathrm{c}^{-}$, and $16 \% \mathrm{MHCII}^{+} \mathrm{CD} 11 \mathrm{c}^{+}$ macrophages (Fig. 5e). The iris displayed 69\% $\mathrm{MHCII}^{-}$, $23 \% \mathrm{MHCII}^{+} \mathrm{CD} 11 \mathrm{c}^{-}$, and $8 \% \mathrm{MHCII}^{+} \mathrm{CD} 11 \mathrm{c}^{+}$macrophages (Fig. 5e).

Next, we used the Mac ${ }^{\mathrm{GFP}}$ fate mapping model to study whole eye (cornea, iris, ciliary body, sclera, vitreous, retina, and choroid) macrophage subsets at steady state. Since data from male and female mice were equivalent at steady state in both models $\left(\mathrm{Crr}^{-/-}\right.$and Mac $\left.{ }^{\mathrm{GFP}}\right)$, experiments were only performed in female mice. Multi-parameter flow cytometry was performed at week 1 , week 4 , and week 8 posttamoxifen administration. As expected, 95\% of microglia were $\mathrm{GFP}^{+}$and remained $\mathrm{GFP}^{+}$through week 8, confirming that microglia are long-lived, self-replenishing tissue resident macrophages (Fig. 5f, g). Similarly, $75 \%$ of $\mathrm{MHCII}^{-}$macrophages were $\mathrm{GFP}^{+}$, and remained $\mathrm{GFP}^{+}$through 8 weeks (Fig. 5h), suggesting that steady state $\mathrm{MHCII}^{-}$macrophages are self-replenishing, tissue resident macrophages. Alternatively, $\mathrm{MHCII}^{+} \mathrm{CD} 11 \mathrm{c}^{-}$macrophages were $91 \% \mathrm{GFP}^{+}$at week 1 and decreased to $65-70 \% \mathrm{GFP}^{+}$at week $4(p<0.01)$ and week 8 ( $p<0.05$, Fig. 5i). Similarly, $\mathrm{MHCII}^{+} \mathrm{CD} 11 \mathrm{c}^{+}$macrophages were $91 \% \mathrm{GFP}^{+}$at week 1 and reduced to $37-38 \%$ $\mathrm{GFP}^{+}$at week 4 and week $8(p<0.001$, Fig. 5j). There were no significant differences in total $\left(\mathrm{GFP}^{-}\right.$and $\left.\mathrm{GFP}^{+}\right)$microglia, $\mathrm{MHCII}^{-}$, or $\mathrm{MHCII}^{+} \mathrm{CD} 11 \mathrm{c}^{+}$macrophage numbers (Fig. S2A-B, S2D). There was a small decrease in total $\mathrm{MHCII}^{+} \mathrm{CD} 11 \mathrm{c}^{-}$macrophages at week 1 (Fig. S2C). These data demonstrate that a portion of $\mathrm{MHCII}^{+}$macrophages are replenished from peripheral monocytes, and that $\mathrm{MHCII}^{+} \mathrm{CD} 11 \mathrm{c}^{+}$macrophages are replenished at a higher rate than $\mathrm{MHCII}^{+} \mathrm{CD} 11 \mathrm{c}$ - macrophages (Fig. 5k).

In order to apply our murine macrophage heterogeneity findings to humans, we re-analyzed a recently published single-cell RNA-seq data set from human RPEchoroid samples [14]. We merged the data from all 7 patients (both with and without endothelial cell [EC] enrichment), performed cell clustering with Seurat v3 [17, 18 ], and visualized the clusters using the uniform manifold approximation and projection (UMAP) technique (Fig S3A). We identified 21 cellular clusters, including EC, pericyte (PC), fibroblast (FB), Schwann (Schw), melanocyte (Mel), retinal pigment epithelium (RPE), retina (Ret), macrophage (Mac), $\mathrm{T}, \mathrm{NK}$, and $\mathrm{B}$ cells (Table S1). Additionally, we found similar EC and
Schw cell heterogeneity (Fig S3B), as previously described [14].

In order to investigate leukocyte heterogeneity, we reclustered the leukocytes (Mac1-3, T, NK, and B1-2), and used an UMAP dimension plot to visualize the cellular gene expression. We identified 11 clusters including 5 macrophage subtypes, 3 effector NK/T cell subsets, 2 populations of B cells, and 1 group of mast cells (Fig. 6a, Table S2). Dot plot visualization identified effector NK/T cells (high CD2, CD8B, NKG7), B cells $(C D 79 A)$, and previously unidentified mast cell (KIT, CPA3) clusters (Fig. 6b). The newly identified 5 macrophage clusters expressed canonical macrophage markers, including CD68, CD163, CD14, and AIF1 (IBA1) markers (Fig. 6b). Mac-A and Mac-B had low PTPRC (CD45) expression, so we investigated microglia markers. Mac-A and Mac-B demonstrated no specific elevation of 8 microglial markers (Fig. S4), which was expected from a sample devoid of retinal tissue. To compare these subsets to our murine macrophages, we queried MHCII and CD11C expression. We found that HLA-DMA and other classical MHCII markers (Fig. S5) were expressed at varying levels in all 5 macrophage subsets (Fig. 6c, e). Alternatively, ITGAX (CD11C) was expressed in Mac-C, Mac-D, and Mac-E (Fig. 6d, f). Therefore, human choroidal macrophages share similar markers to $\mathrm{MHCII}^{+} \mathrm{CD} 11 \mathrm{c}^{-}$and $\mathrm{MHCII}^{+} \mathrm{CD} 11 \mathrm{c}^{+}$murine macrophages.

We next queried the contribution of each patient to our 5 macrophage subsets to determine if any subset is disease-associated. We found that the macula of Donor 4, who had nAMD, represented $78.3 \%$ of cells in Mac-E (Fig. 6g, Table S3). No other cluster demonstrated $>50 \%$ of cells from one patient, suggesting that Mac-E could be nAMD-associated and potentially pro-angiogenic.

Finally, we performed differential expression analysis on each macrophage subset (Table S4), followed by gene ontology (GO) enrichment to determine if any subset was enriched for vascular biology terms (Table S5). We found 8.3-fold enrichment for angiogenesis in upregulated genes from the Mac-B population (FDR $q=4.9 \times$ $10^{-17}$, Fig. 7a). Cysteine-rich angiogenic inducer 61 (CYR61) is an extracellular matrix protein and endoglin $(E N G)$ is a transmembrane glycoprotein. Knockdown of Cyr61 [27] or Eng [28] reduce retinal neovascularization 


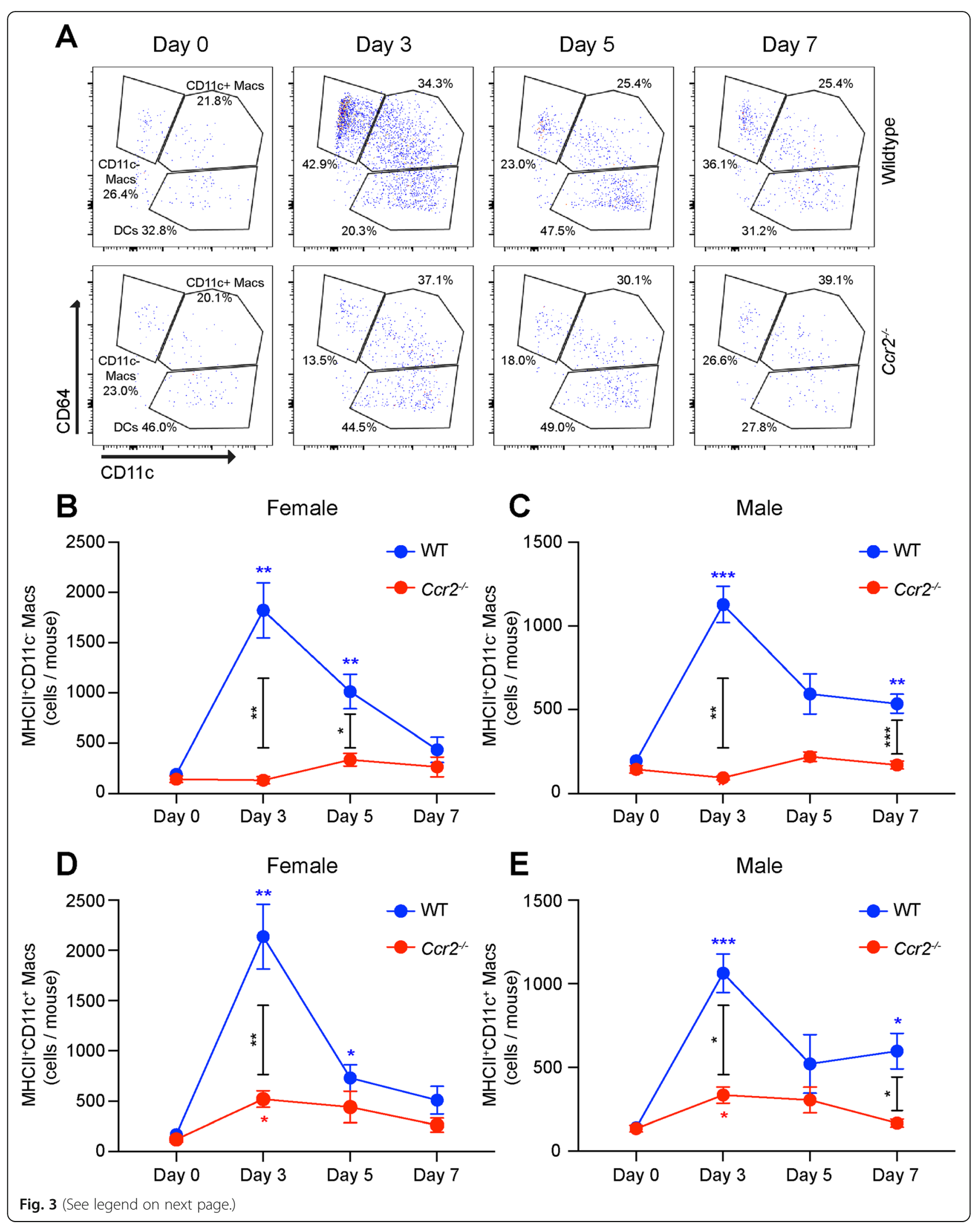


(See figure on previous page.)

Fig. 3 Ablated $\mathrm{MHCll}^{+} \mathrm{CD} 11 \mathrm{c}^{-}$and decreased $\mathrm{MHCI}{ }^{+} \mathrm{CD} 11 \mathrm{c}^{+}$macrophage numbers in $\mathrm{CCr}^{-/-}$mice in response to laser injury. a Representative flow cytometry pseudocolor plots from wildtype and $\mathrm{CCr}^{-/-}$female mice from day 0 , day 3, day 5, and day 7. $\mathrm{MHClI}^{+} \mathrm{CD} 11 \mathrm{c}^{-}$macrophage numbers peaked in WT mice on day 3 and were completely unchanged in $\mathrm{CCr}^{-/-}$female (b) and male (c) mice. $\mathrm{MHCII}^{+} \mathrm{CD} 11 \mathrm{c}^{+}$macrophage numbers peaked in WT mice on day 3 and were blunted in $\mathrm{Ccr}{ }^{-1-}$ female (d) and male (e) mice. ${ }^{*} p<0.05$; ${ }^{* *} p<0.01$; ${ }^{* * *} p<0.001$. Colored asterisk $=$ significant difference from day 0 within genotype (blue $=\mathrm{WT}$, red $=\mathrm{Ccr} 2^{-1-}$ mice). Black asterisk $=$ significant difference between genotypes on day 3, day 5, or day 7. $N=8-11$ per group in both male and female mice. Macrophage numbers were compared using the BrownForsythe and Welch ANOVA followed by Dunnett's T3 multiple comparison

in the oxygen-induced retinopathy (OIR) mouse model. $C Y R$ and ENG were upregulated 2.1- and 3.2-fold in Mac-B, respectively (Fig. 7c, d). Tie2 (TEK) and LEPR are cell surface receptors for angiopoietin and leptin, respectively. Both macrophage-specific Tie 2 knockout mice [29] and leptin receptor antagonism [30] inhibit laser-induced CNV. TEK and LEPR expression were increased by 2.1- and 2.4-fold in Mac-B (Fig. 7e, f). ID1 and hypoxia-inducible factor (HIF) 2alpha (EPAS1) are transcription factors upregulated by 2.6- and 4.9-fold, respectively, in Mac-B (Fig. $7 \mathrm{~g}, \mathrm{~h}$ ). $I d 1^{-/-}$mice demonstrate reduced laser-induced $\mathrm{CNV}$ area and retinal neovascularization during OIR [31], and HIF-2alpha increases VEGF expression during hypoxia [32]. Therefore, Mac-B demonstrated increased expression of proangiogenic genes including extracellular signals, cell surface receptors, and transcription factors.

Although not as significant as the angiogenesis GO term in Mac-B, the Mac-D subset displayed 11.7-fold enrichment for regulation of endothelial cell migration (FDR $q=0.02$, Fig. 7a). MicroRNA 29a (MIR29A) is expressed by macrophages and stimulates angiogenesis by downregulating anti-angiogenic genes like TIMP3 [33]. TIMP3 is the causative mutation for Sorsby's macular dystrophy, which demonstrates early onset CNV, and inhibits angiogenesis by blocking VEGF signaling [34]. MIR29A was increased 2.0-fold in Mac-D (Fig. 7i). Tumor necrosis factor (TNF) and platelet-derived growth factor B (PDGFB) are secreted ligands that stimulate angiogenesis in the laser-induced $\mathrm{CNV}$ model [35, 36]. Both TNF and PDGFB were increased 2.2- and 2.1-fold in the Mac-D subset (Fig. 7j, k). Thus, Mac-D has the potential to be an additional pro-angiogenic population. Interestingly, no Mac-D upregulated genes in the regulation of endothelial cell migration GO term were shared with the Mac- $B$ increased genes from the angiogenesis GO term.

Mac-E, the nAMD-associated population, was enriched 5.2-fold for cytokine-mediated signaling pathway (FDR $q=1.8 \times 10^{-8}$, Fig. 7a). Due to our stringent dispensability cutoff, Mac-E enrichment for positive regulation of vasculature development (5.7-fold, FDR $q$ $=6.6 \times 10^{-3}$ ) was subsumed by cytokine-mediated signaling pathway. MIR29A, which was the only gene unique to the positive regulation of vasculature development GO term, was upregulated 2.7-fold in MacE (Fig. 7i). TNF and PDGFB were included in both GO terms and increased by 2.6- and 3.3-fold respectively in Mac-E (Fig. 7j, k). In addition, the CXCR4 receptor, which is expressed on macrophages and is necessary for retinal and choroidal neovascularization [37], was expressed 2.5-fold more in Mac-E than other Mac subsets and included in both enriched GO terms (Fig. 7l). And finally, Mac-E demonstrated the highest VEGFA (2.7-fold, Fig. $7 \mathrm{~m}$ ) and lowest THBS1 (Thrombospondin1, 3.2-fold downregulated, Fig. 7n) expression, the two central pro- and anti-angiogenic ocular genes in $\mathrm{CNV}$ [38], respectively. These analyses demonstrate similar macrophage heterogeneity between mice and humans, and support the concept of pro-angiogenic choroidal macrophage subsets, which could be future therapeutic targets for nAMD.

\section{Discussion}

In this report, we used the $\mathrm{Ccr} 2^{-/-}$mouse and the Mac ${ }^{\mathrm{GFP}}$ fate mapping model to investigate how macrophage origin impacts macrophage heterogeneity at steady state and during experimental CNV. At steady state, our data suggest a model where microglia and $\mathrm{MHCII}^{-}$macrophages are selfsustaining, tissue resident macrophages (Fig. 8a). In contrast, $\mathrm{MHCII}^{+}$macrophages are partially replenished by blood monocytes, with $\mathrm{MHCII}^{+} \mathrm{CD} 11 \mathrm{c}^{+}$macrophages demonstrating a larger proportion derived from the monocyte pool (Fig. 8a). After injury, classical monocytes infiltrate the choroid and become $\mathrm{MHCII}^{-}, \mathrm{MHCII}^{+} \mathrm{CD} 11 \mathrm{c}^{-}$, and $\mathrm{MHCII}^{+} \mathrm{CD} 11 \mathrm{c}^{+}$ macrophages (Fig. 8b). Additionally, tissue resident macrophages expand in response to injury and contribute to the $\mathrm{MHCII}^{-}$and $\mathrm{MHCII}^{+} \mathrm{CD} 11 \mathrm{c}^{+}$macrophage populations. Finally, a small portion of $\mathrm{MHCII}^{+} \mathrm{CD} 11 \mathrm{c}^{+}$macrophages are not accounted for in the $\mathrm{Ccr}^{-/-}$mouse or the $\mathrm{Mac}^{\mathrm{GFP}}$ model, suggesting potential involvement of non-classical monocytes.

Retinal microglia are the most well-studied macrophage in the eye, and are known to be long-lived, selfreplenishing tissue resident macrophages with no contribution from the monocyte pool [22]. Our data independently confirm this prior work at steady state (Fig. $5 \mathrm{~g})$. After laser injury, microglia are unchanged by laser or Ccr2-deficiency (Fig. 2d, e), suggesting that microglia numbers are relatively unaffected by laser injury to the 


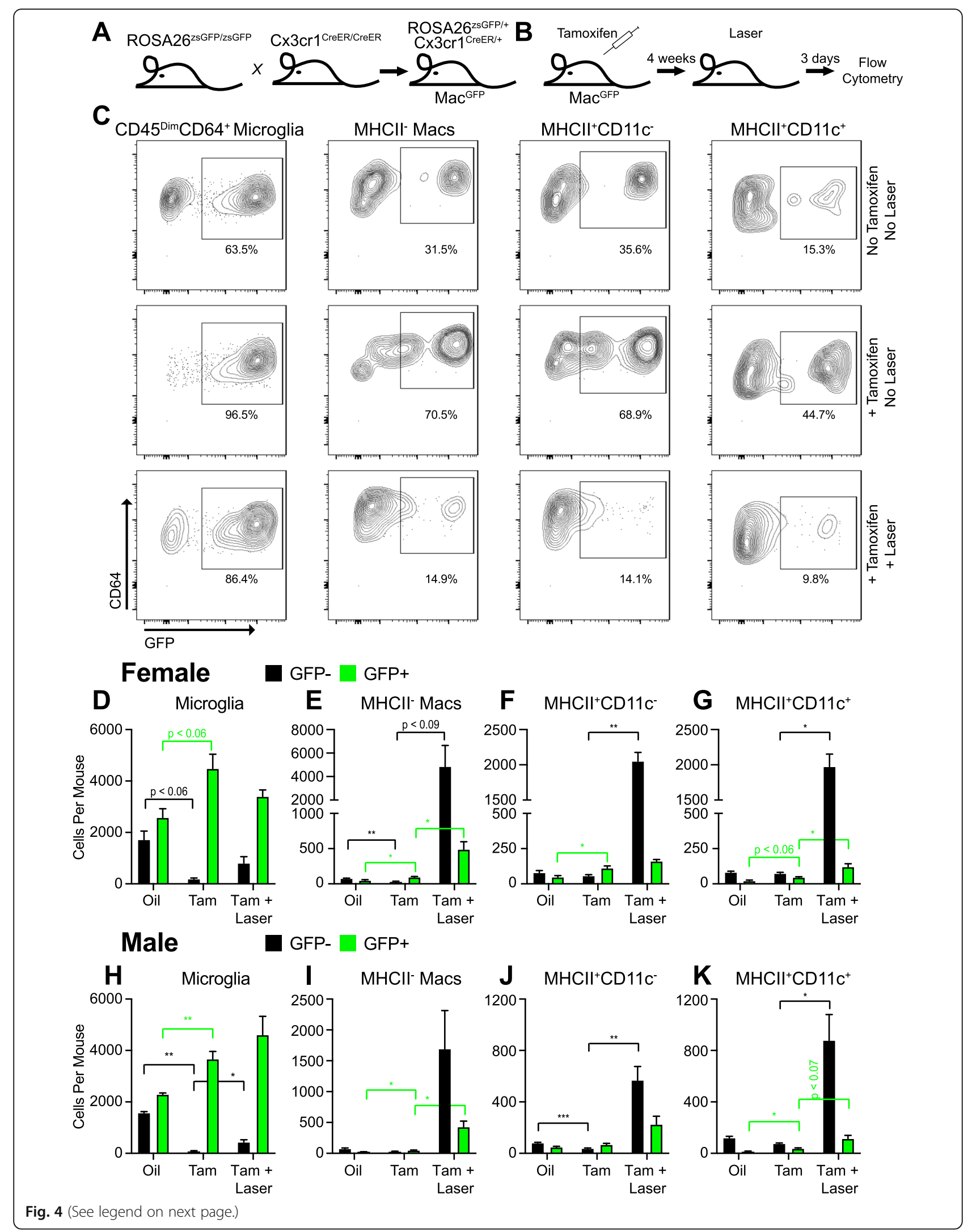


(See figure on previous page.)

Fig. 4 Fate mapping of macrophages subsets after laser injury. a Breeding strategy for generation of Mac GFP mice. b Experimental design for fate mapping of tissue resident macrophages. $\mathbf{c}$ Representative contour plots of GFP' ${ }^{+}$vs. GFP ${ }^{-}$macrophage subsets. $\mathbf{d}-\mathbf{k}$ Quantitative analysis of GFP and GFP ${ }^{-}$macrophage numbers for each subset in female $(\mathbf{d}-\mathbf{g})$ and male $(\mathbf{h}-\mathbf{k})$ mice. Oil $=$ corn oil vehicle control, Tam $=$ Tamoxifen. ${ }^{*} p<0.05$; ${ }^{* *} p<0.01 ;{ }^{* *} p<0.001$. Color $=$ GFP- (black) or GFP+ (green) cells. $N=3-9$ in male mice and $N=4-9$ in female mice per group. Macrophage numbers were compared using the Brown-Forsythe and Welch ANOVA followed by Dunnett's T3 multiple comparison

choroid. An important limitation to our data is that because we distinguish microglia as $\mathrm{CD} 45^{\mathrm{dim}} \mathrm{CD} 64^{+}$, activated microglia could not be included, which can express $\mathrm{CD} 45^{\text {high }} \mathrm{CD}^{+} 4^{+} \mathrm{MHCII}^{+}$markers. Those cells could be mischaracterized as $\mathrm{MHCII}^{+} \mathrm{CD} 11 \mathrm{c}^{+}$macrophages, which could be an alternative explanation for the small expanded tissue resident $\mathrm{GFP}^{+} \mathrm{MHCII}^{+} \mathrm{CD} 11 \mathrm{c}^{+}$ population (Figs. 4g and Figs. 5k). How laser injury impacts microglia gene expression and function is less understood. Microglia are known to increase VEGF expression after laser injury [39], potentially implicating microglia as pro-angiogenic. Alternatively, depletion of $\mathrm{CD}_{11} \mathrm{~b}^{+}$cells in the retina prior to laser injury, which depletes retinal microglia in addition to other cell types, has no effect upon $\mathrm{CNV}$ area [40], suggesting that microglia are not necessary for $\mathrm{CNV}$ compared to monocyte-derived macrophages. Because most prior studies do not sufficiently discriminate between microglia and infiltrating macrophages using multi-parameter flow cytometry or advanced fate mapping methods, the role of microglia during $\mathrm{CNV}$ remains unclear and more advanced methodologies will be needed to determine their function.

Similar to retinal microglia and synovial macrophages [41], $\mathrm{MHCII}^{-}$macrophages are self-replicating with no replenishment from the peripheral monocyte pool at steady state (Fig. 5h). Since only $75 \%$ of $\mathrm{MHCII}^{-}$macrophages were $\mathrm{GFP}^{+}$, we suspect that this population is either $\mathrm{Cx} 3 \mathrm{cr} 1^{\text {low }}$ or heterogeneously $\mathrm{Cx} 3 \mathrm{Cr}^{+}$. Flow cytometry from ocular sub-compartments identifies that $\sim 60 \%$ of iris and ciliary body macrophages and $<20 \%$ of choroidal macrophages are $\mathrm{MHCII}^{-}$[42]. Our data similarly find that $70 \%$ of iris macrophages are $\mathrm{MHCII}^{-}$, but we find that $50 \%$ of choroidal macrophage are $\mathrm{MHCII}^{-}$ (Fig. 5e). The difference between our data and the prior is both mouse background (Balb/c vs. C57BL6/J) and that we distinguish dendritic cells using CD64; since dendritic cells are $\mathrm{MHCII}^{+}$, their inclusion will decrease the fractional abundance of $\mathrm{MHCII}^{-}$macrophages in the prior study. Prior fate mapping studies show that iris and ciliary body macrophages are self-replenishing while choroidal macrophages are replenished from blood monocytes [13]. It is interesting that although $75 \%$ of $\mathrm{MHCII}^{-}$macrophages reside in the iris (Fig. 5d), all $\mathrm{MHCII}^{-}$macrophages are self-replenishing at steady state. This suggests that both cell surface markers and tissue microenvironment are equally important for determining cell fate.

After laser injury, $\mathrm{MHCII}^{-}$macrophages increase dramatically and are significantly reduced but not abolished in $\mathrm{Ccr}^{-/-}$mice (Fig. 2g, h). In $\mathrm{Mac}^{\mathrm{GFP}}$ mice, $\mathrm{GFP}^{+} \mathrm{MHCII}^{-}$macrophage numbers grew by $\sim 400$ cells in male and female mice (Fig. 4e, i), which is nearly identical to the number of $\mathrm{MHCII}^{-}$macrophages found in $\mathrm{Cr} 2^{-/-}$male and female mice after laser injury. These data suggest that after laser injury, $\mathrm{MHCII}^{-}$macrophages are $90 \%$ derived from classical monocytes and the remaining $10 \%$ expand from tissue resident macrophages (Fig. 8b). The fact that peripheral blood classical monocytes are $~ 80 \% \mathrm{MHCII}^{-}$and $~ 20 \% \mathrm{MHCII}^{+}$[43] supports our finding that the majority of $\mathrm{MHCII}^{-}$macrophages after laser injury are derived from classical monocytes.

We identified two $\mathrm{MHCII}^{+}$macrophage populations: $\mathrm{MHCII}^{+} \mathrm{CD} 11 \mathrm{c}^{+}$and $\mathrm{MHCII}^{+} \mathrm{CD} 11 \mathrm{c}^{-}$. At steady state, both $\mathrm{MHCII}^{+}$macrophage populations demonstrate replenishment from the peripheral monocyte pool (Fig. 5i, j). $\mathrm{MHCII}^{+} \mathrm{CD} 11 \mathrm{c}^{-}$macrophages are $70 \%$ tissue resident with $30 \%$ derived from peripheral blood monocytes over a 2month period (Fig. 8a). $\mathrm{MHCII}^{+} \mathrm{CD} 11 \mathrm{c}^{+}$macrophages show more frequent turnover, are 30\% tissue resident, and $70 \%$ replenished from monocytes. CD11c is an alpha integrin that dimerizes with CD18 to form complement receptor 4 (CR4) [44]. The function of CR4 in macrophages includes adhesion to the vasculature and is important for tissue recruitment at steady state [45], potentially explaining why $\mathrm{MHCII}^{+} \mathrm{CD} 11 \mathrm{c}^{+}$ macrophages show more contribution from the monocyte pool. Additionally, $\mathrm{MHCII}^{+} \mathrm{CD} 11 \mathrm{c}^{-}$macrophages displayed higher numbers in the iris compared to the choroid (Fig. 5d, e). It is possible that the ocular sub-compartment is equally as important as CD11c expression in determining tissue resident vs monocyte-derived macrophage origin.

After laser injury, the increased $\mathrm{MHCII}^{+} \mathrm{CD} 11 \mathrm{c}^{-}$macrophages numbers reflect an influx of classical monocytes differentiating into $\mathrm{MHCII}^{+} \mathrm{CD} 11 \mathrm{c}^{-}$macrophages (Fig. 8b). This murine $\mathrm{MHCII}^{+} \mathrm{CD} 11 \mathrm{c}^{-}$macrophage population is similar to the human Mac-A and Mac-B subsets (Fig. 6). Interestingly, Mac-B was 8.3-fold enriched for angiogenesis genes (Fig. 7b), including ligands (CYR61, ENG), receptors (TEK, LEPR), and transcription factors (ID1, EPAS1). Although Mac-B was not as over-represented as Mac-E, $37 \%$ of cells in Mac-B were derived from the 


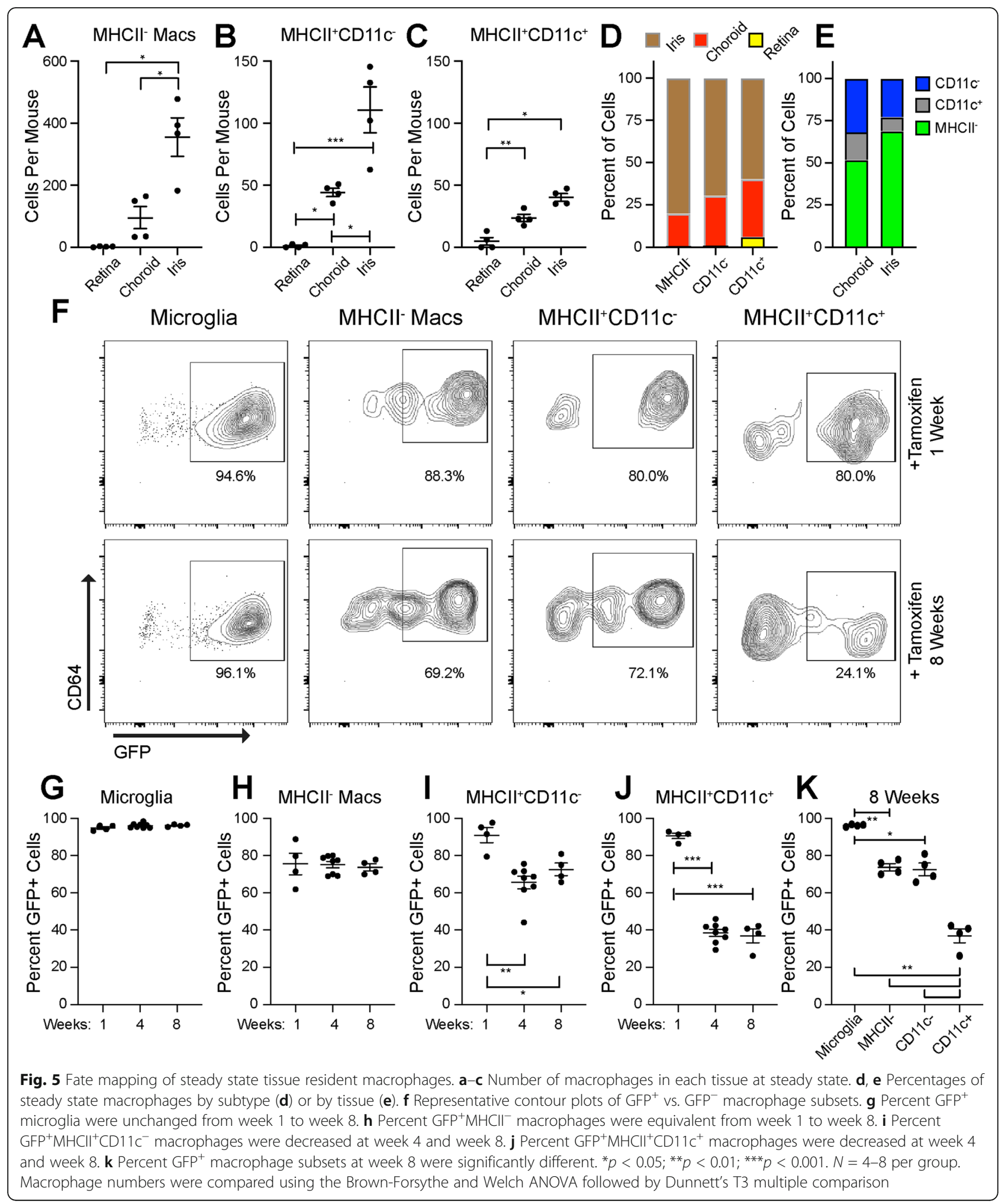

macula of a patient with nAMD. Alternatively, as macrophage depletion causes choroidal vascular atrophy [10], Mac-B could support steady state choroidal vasculature homeostasis. Considering that $\mathrm{MHCII}^{+} \mathrm{CD} 11 \mathrm{c}^{-}$macrophages are derived from classical monocytes, which drive angiogenesis in the choroid, and Mac-B, which is 


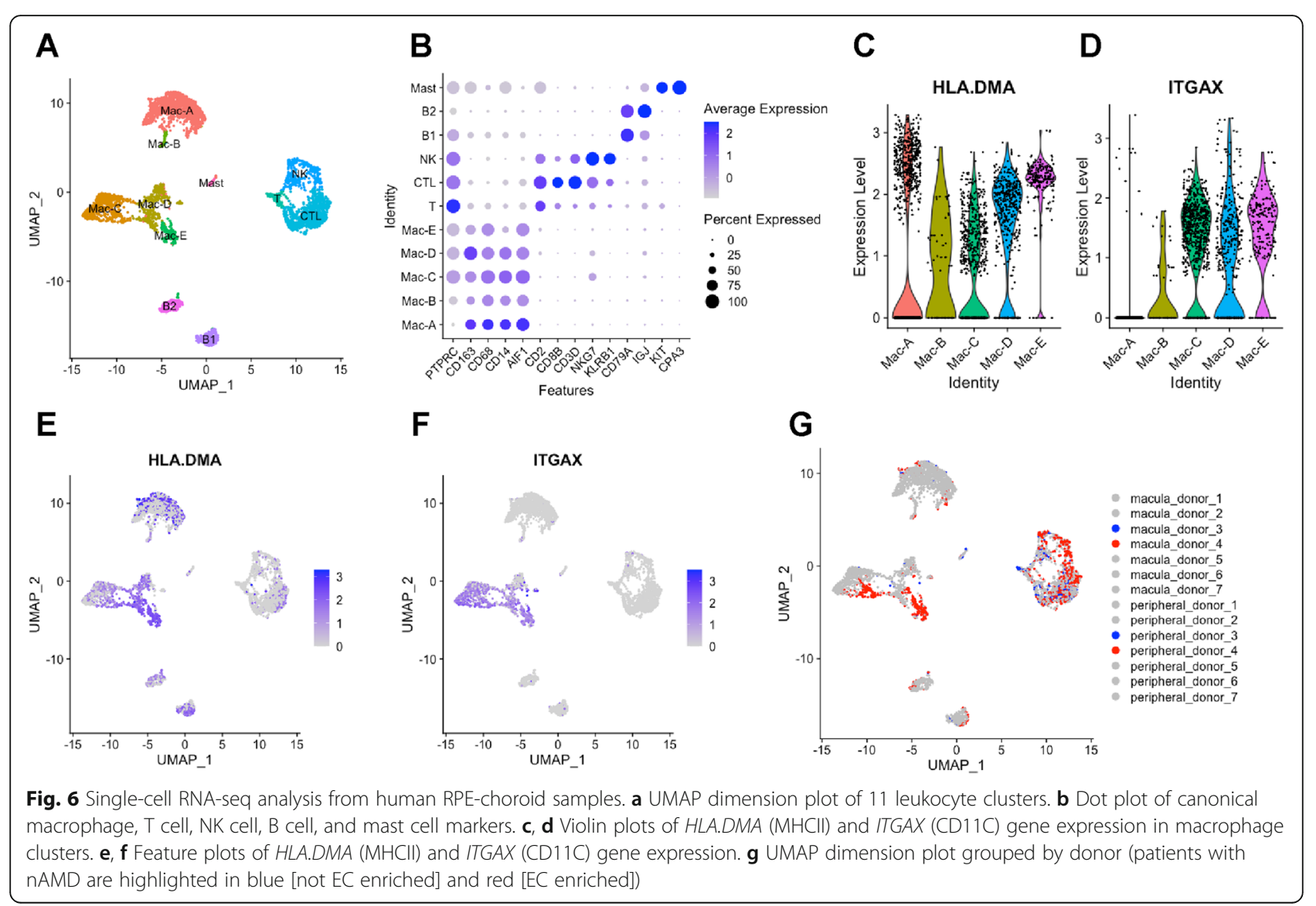

$\mathrm{MHCII}^{+} \mathrm{CD} 11 \mathrm{c}^{-}$, is enriched for angiogenesis genes (Fig. $7 \mathrm{~b})$, specific anti-Mac-B therapy could be a novel therapeutic for nAMD.

After laser injury, $\mathrm{MHCII}^{+} \mathrm{CD} 11 \mathrm{c}^{+}$macrophages are derived from classical monocytes, expanded tissue resident macrophages, and potentially from non-classical monocytes (Fig. 8b). Human scRNA-seq analysis identifies Mac-C, Mac-D, and Mac-E as $\mathrm{MHCII}^{+} \mathrm{CD} 11 \mathrm{C}^{+}$ macrophages (Fig. 6). These data demonstrate that $\mathrm{MHCII}^{+} \mathrm{CD} 11 \mathrm{c}^{+}$macrophages are both heterogeneous in murine origin after laser injury, and heterogeneous in the human choroid. Interestingly, Mac-D was enriched for regulation of endothelial cell migration, and Mac-E demonstrated enrichment for cytokine-mediated signaling pathway, which included the positive regulation of vasculature development term (Fig. 7a). In support of a $\mathrm{CD}_{11 \mathrm{c}^{+}}$disease-associated macrophage, CR4 is capable of binding Factor $\mathrm{H} \mathrm{[46]} \mathrm{and} \mathrm{is} \mathrm{important} \mathrm{for} \mathrm{phagocyt-}$ osis of iC3b opsonized particles [47]. Therefore, CD11 $\mathrm{c}^{+}$ macrophages are critical for complement-mediated processes (which are strongly linked to AMD). Furthermore, Mac-E was strongly derived (78.3\% of cells) from a patient with nAMD, expressed the highest VEGFA, and lowest THBS1, which are two central angiogenic factors in nAMD. The subset of classical monocyte-derived $\mathrm{MHCII}^{+} \mathrm{CD} 11 \mathrm{c}^{+}$macrophages are a potential key proangiogenic macrophage subtype.

Interestingly, the Mac-D and Mac-E upregulated genes for the regulation of endothelial cell migration and positive regulation of vasculature development GO terms were very similar to one another, but completely nonoverlapping with the angiogenesis genes from Mac-B. Therefore, our analysis has uncovered two discrete macrophage-driven angiogenesis functions in the choroid.

We identified a number of interesting sex-specific differences in the laser-induced CNV model. First, female $\mathrm{Ccr}^{-/-}$mice demonstrated reduced $\mathrm{CNV}$ area, while males did not (Fig. 2a-d). This is in partial agreement with prior reports that showed $\sim 75 \%$ inhibition of CNV in female $\mathrm{Ccr}^{-/-}$mice [23] compared to only $38 \%$ decreased CNV area in male $\mathrm{Ccr} 2^{-/-}$mice [48]. Similarly, female patients demonstrate increased prevalence of nAMD [24, 25]. When observing absolute CNV area, this difference appears to be due to larger $\mathrm{CNV}$ area in WT female compared to male mice. Additionally, female WT mice on average displayed twice the number of macrophages compared to males (Figs. 2 and 3). 


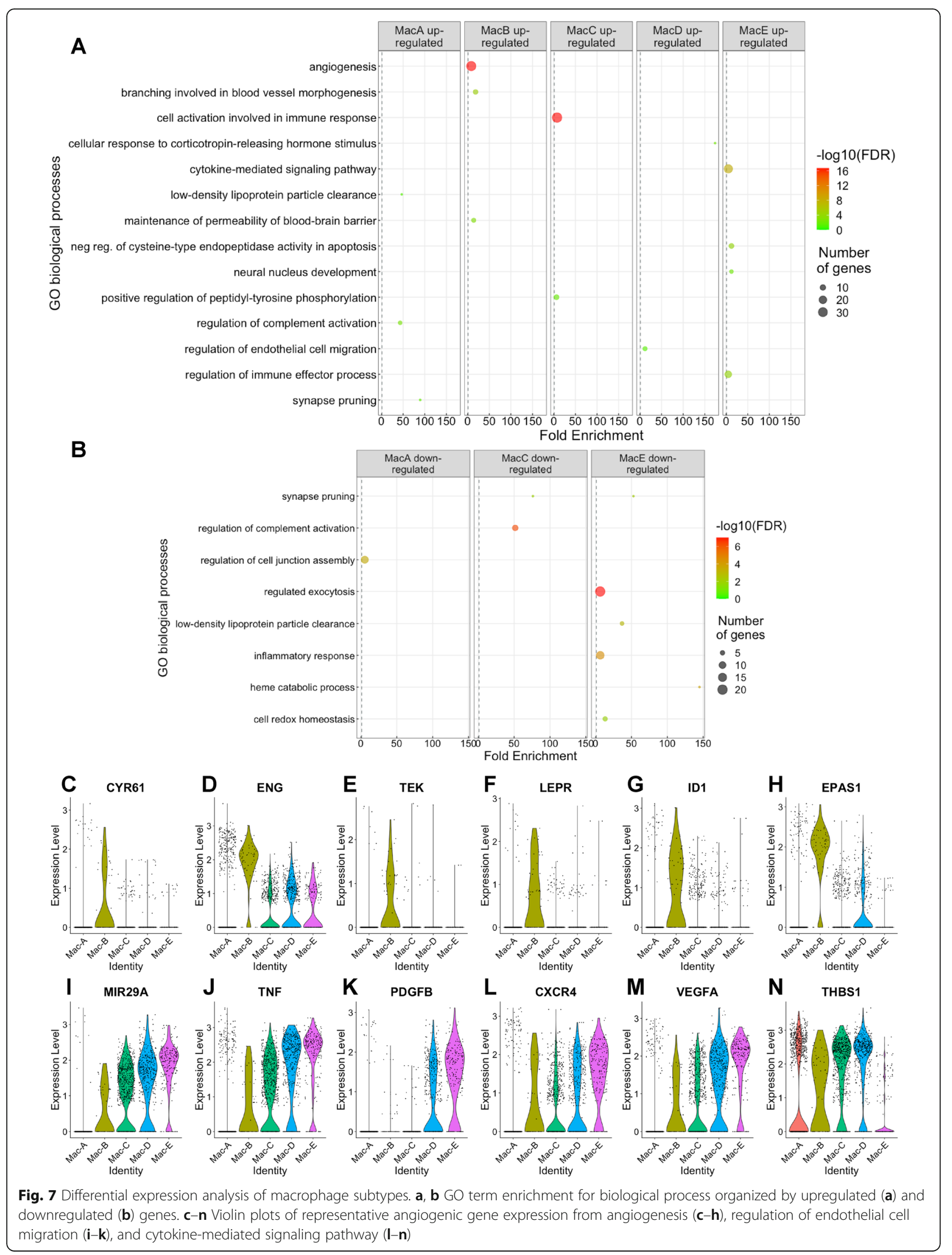




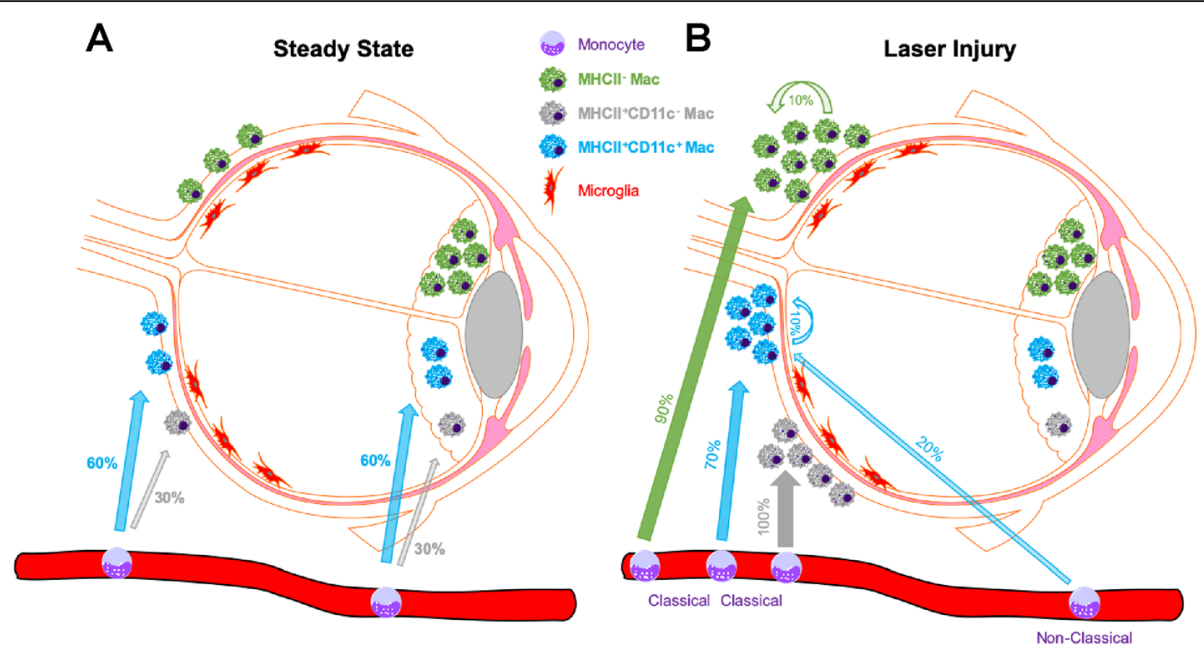

Fig. 8 Model of ocular macrophage lineage during steady state and laser injury. a At steady state, microglia (red) and MHCII' macrophages (green) are tissue resident, self-sustaining, and long-lived macrophages. MHCII+ macrophages (CD11 $\mathrm{c}^{-}$[gray] and $\left.\mathrm{CD} 11 \mathrm{c}^{+}[\mathrm{blue}]\right)$ are partially self-sustaining and partially recycled from the peripheral blood monocyte pool (numbers indicate percentage replenished from blood monocytes). b After laser injury, $\mathrm{MHCl}^{-}$macrophages (green) are derived from classical monocytes (90\%) and from expanded tissue resident macrophages (10\%). MHCII ${ }^{+} \mathrm{CD} 11 \mathrm{C}^{-}$ macrophages (gray) are 100\% derived from classical monocytes. $\mathrm{MHCII}^{+} \mathrm{CD} 11 \mathrm{c}^{+}$macrophages are derived from classical monocytes $(70 \%)$, non-classical monocytes (20\%), and expanded tissue resident macrophages (10\%)

However, male WT mice showed sustained increases in $\mathrm{MHCII}^{-}, \mathrm{MHCII}^{+} \mathrm{CD} 11 \mathrm{c}^{-}$, and $\mathrm{MHCII}^{+} \mathrm{CD} 11 \mathrm{c}^{+}$macrophage numbers on day 7 , which was not observed in female mice. These data suggest that higher numbers of early macrophages in female mice caused larger $\mathrm{CNV}$ area, and/or prolonged macrophage presence decreased $\mathrm{CNV}$ area in male mice.

Our studies have a few important limitations. First, we used whole eye, including cornea, iris, ciliary body, vitreous, retina, and choroid for our studies. We made this decision for optimal rigor and reproducibility, and to prevent uneven ocular dissections from creating variance in our results. Because the site of injury is the choroid with some perturbations of the overlying retina, our increased macrophage numbers after laser injury most likely reflect choroidal and subretinal macrophages. However, we cannot exclude contributions from other ocular compartments. Secondly, the $C x 3 c r 1^{\text {CreER }}$ transgene does demonstrate some expression without tamoxifen treatment, which is consistent with prior reports [49]. We made key comparisons between corn oil vehicle control and tamoxifen treatment, and demonstrated equivalent $\mathrm{GFP}^{+}$blood monocytes 4-6 weeks after tamoxifen treatment compared to vehicle control (Fig. S1), in order to minimize noise created by the leaky $C \times 3 c r 1^{\text {CreER }}$ transgene. Nevertheless, rare non-specific $\mathrm{GFP}^{+}$cells cannot be excluded. Lastly, we compared the number of $\mathrm{Cr} 2^{-/-}$macrophages on day 3 vs. day 0 to the number of increased $\mathrm{GFP}^{+}$macrophages on day 3 after laser treatment. We found equivalent numbers for $\mathrm{MHCII}^{-}$macrophages from male and female mice, but less $\mathrm{GFP}^{+}$compared to $\mathrm{Ccr} 2^{-1-}$ macrophages for the $\mathrm{MHCII}^{+} \mathrm{CD} 11 \mathrm{c}^{+}$subset in male and female mice. From this data, we concluded that all $\mathrm{MHCII}^{-}$macrophages were either derived from classical monocytes or tissue resident macrophages, and that $\mathrm{MHCII}^{+} \mathrm{CD} 11 \mathrm{c}^{+}$macrophages were derived from classical monocytes, tissue resident macrophages, and a third source that is either non-classical monocytes or activated microglia. However, these are two independent experiments, which may not be directly comparable, and these interpretations need to be confirmed with mice specifically deficient in non-classical monocytes.

\section{Conclusions}

In summary, we demonstrated the presence of $\mathrm{MHCII}^{-}$, $\mathrm{MHCII}^{+} \mathrm{CD} 11 \mathrm{c}^{-}$, and $\mathrm{MHCII}^{+} \mathrm{CD} 11 \mathrm{c}^{+}$macrophages in mouse eyes. Using the laser-induced $\mathrm{CNV}$ model, $\mathrm{Ccr} 2^{-/-}$ mice, and Mac ${ }^{\text {GFP }}$ fate mapping studies, we showed that $\mathrm{MHCII}^{+} \mathrm{CD} 11 \mathrm{c}^{-}$macrophages were entirely derived from classical monocytes, $\mathrm{MHCII}^{-}$macrophages originated from classical monocytes and an expansion of tissue resident macrophages, and $\mathrm{MHCII}^{+} \mathrm{CD} 11 \mathrm{c}^{+}$macrophages were derived from classical monocytes, potential non-classical monocytes, and an expansion of tissue resident macrophages. In human choroidal macrophages, we identified $\mathrm{MHCII}^{+} \mathrm{CD} 11 \mathrm{C}^{-}$and $\mathrm{MHCII}^{+} \mathrm{CD} 11 \mathrm{C}^{+}$populations. Two discrete macrophage-driven pro-angiogenic clusters were found in the $\mathrm{MHCII}^{+} \mathrm{CD} 11 \mathrm{C}^{-}$and $\mathrm{MHCII}^{+} \mathrm{CD} 11 \mathrm{C}^{+}$ groups. These studies demonstrate that macrophage heterogeneity exists in the mouse and human choroid, that pro-angiogenic macrophages exist, and are a potential new therapeutic target for nAMD. 


\section{Supplementary Information}

The online version contains supplementary material available at https://doi. org/10.1186/s12974-020-02010-0.

Additional file 1: Figure S1. Gating strategy and analysis of peripheral blood in male Mac ${ }^{\text {GFP }}$ mice. (A) Gating strategy for the identification of singlet, $\mathrm{CD} 45^{+}$cells are shown across the top. B cells $\left(\mathrm{CD} 19^{+}\right.$, bottom right), T cells (CD4/CD8 ${ }^{+}$, bottom right), NK Cells (CD11 b ${ }^{+} \mathrm{NK} 1.1^{+}$, bottom middle), eosinophils (CD11 b+SSC- $\mathrm{H}^{+}$Ly $\left.6 \mathrm{G}^{-}\right)$, and neutrophils

$\left(C D 11 b^{+} L_{6} 6 G^{+}\right)$are delineated. Monocytes are identified from the $\mathrm{CD}_{11 b^{+} \text {Ly6G SSC-H }}^{\text {Low }}$ group (Not PMNs) as CD $115^{+}$and either $\mathrm{GFP}^{+}$or GFP' from oil (B), tamoxifen (Tam) Early (1 week, C), or Tam Late (4-6 weeks, D). Quantitative analysis of monocytes (E), NK cells (F), T cells (G), eosinophils $(H)$, neutrophils $(I)$, and B cells $(H) .{ }^{*} p<0.05$, ${ }^{* * *} p<0.001$. $\mathrm{GFP}^{+}$cells were compared using the Brown-Forsythe and Welch ANOVA followed by Dunnett's T3 multiple comparison.

Additional file 2: Figure S2. Absolute macrophage numbers at steady state in Mac GFP mice. Total number (GFP ${ }^{+}$and GFP) of microglia (A), $\mathrm{MHCll}^{-}(\mathrm{B}), \mathrm{MHCl}^{+} \mathrm{CD} 11 \mathrm{C}^{-}(\mathrm{C})$, and $\mathrm{MHCl}^{+} \mathrm{CD} 11 \mathrm{C}^{+}(\mathrm{D})$ macrophages at week 1, week 4, and week 8 in tamoxifen-treated Mac ${ }^{\text {GFP }}$ mice. ${ }^{*} p<$ $0.05,{ }^{* *} p<0.01$. Comparisons were made using the Brown-Forsythe and Welch ANOVA followed by Dunnett's T3 multiple comparison.

Additional file 3: Figure S3. Singe cell RNA-seq analysis from human RPE-choroid samples. (A) UMAP dimension plot of 21 cell clusters. (B) Dot plot of canonical expression markers for each cell type. (C) Dot plot of canonical leukocyte markers confirming specific expression in macrophage (Mac), T (T cell), NK (NK cell), and B (B cell) clusters.

Additional file 4: Figure S4. Violin plots of microglia-specific genes. Violin plots of microglia-specific genes demonstrate no consistently increased expression of any gene in the Mac-A or Mac-B subsets.

Additional file 5: Figure S5. Violin plots of classical MHCII genes. Violin plots of classical MHCll genes showed that the majority of choroidal macrophages were $\mathrm{MHCl}^{+}$.

Additional file 6: Table S1. Top 20 genes for each cluster from full human choroidal sc-RNA-seq data set. Excel file of gene names, cluster, adjusted $p$-value (p_val_adj), percent of cells expressing gene (pct.1 = current cluster, pct.2 = all other clusters), fold change (avg_logFC = natural log fold change), and raw $p$-value ( $p \_$val).

Additional file 7: Table S2. Top 25 genes for each cluster of the leukocytes from human choroidal sc-RNA-seq data set. Excel file of gene names, cluster, adjusted $p$-value (p_val_adj), percent of cells expressing gene (pct.1 = current cluster, pct.2 = all other clusters), fold change (avg_logFC = natural log fold change), and raw $p$-value ( $\left.p \_v a l\right)$.

Additional file 8: Table S3. Number and percentage of cells from each patient that contributed to each leukocyte cluster. Number of cells, ratio of cells, phenotype of patient, and enrichment of sample from each human donor.

Additional file 9: Table S4. List of differentially expressed genes between macrophage subtypes. Excel file of gene names, cluster, adjusted p-value (p_val_adj), percent of cells expressing gene (pct.1 = current cluster, pct.2 = all other clusters), fold change (avg_logFC = natural log fold change), and raw $p$-value ( $p \_$val).

Additional file 10: Table S4. GO and REVIGO outputs for up- and down-regulated genes from each macrophage subtype. For GO tabs: Excel file of GO terms, description of GO term, p-value, FDR q-value, fold enrichment, number of genes expressed in macrophages $(N)$, number of genes in GO term (B), number of differentially expressed genes (n), number of differentially expressed genes in the GO term (b), and the specific genes that were differentially expressed in the GO term. For REVIGO tabs: Excel file of GO term (term_ID), description of GO term, frequency, plotting information, log10 p-value, uniqueness, dispensability, and whether or not the term was eliminated ( $0=$ no, $1=$ yes) due to dispensability.

\section{Abbreviations}

nAMD: Neovascular age-related macular degeneration; AMD: Age-related macular degeneration; CNV: Choroidal neovascularization; WT: Wildtype; RPE: Retinal pigment epithelium; VEGF: Vascular endothelial growth factor;
MHCll: Major histocompatibility complex II; CCR2: C-C chemokine receptor 2; GO: Gene ontology; PCA: Principal component analysis; PC: Principal component; EC: Endothelial cell; UMAP: Uniform manifold approximation and projection; PC: Pericyte; FB: Fibroblast; Schw: Schwann; Mel: Melanocyte; Ret: Retina; Mac: Macrophage; TNF: Tumor necrosis factor; PDGFB: Plateletderived growth factor $B$; scRNA-seq: Single cell RNA-sequencing; CR4: Complement receptor 4; CYR61: Cysteine-rich angiogenic inducer 61; ENG: Endoglin; HIF: Hypoxia-inducible factor; MIR29A: MicroRNA 29a; THBS1: Thrombospondin-1; FDR: False discovery rate

\section{Acknowledgements}

Not applicable.

\section{Authors' contributions}

SD designed research studies, conducted experiments, acquired data, and wrote the manuscript. BRT analyzed data and critically reviewed the manuscript. HMM designed research studies and critically reviewed the manuscript. CMC designed research studies, analyzed data, and critically reviewed the manuscript. HRP designed research studies, and critically reviewed the manuscript. JAL designed research studies, conducted experiments, acquired data, analyzed data, and wrote the manuscript. All author(s) read and approved the final manuscript.

\section{Funding}

BRT was supported by NIH grant R01 EY025799. HM is supported by NIH grant R01 HL 134375 (Diversity Supplement). CMC was supported by a Lupus Research Alliance Novel Research Grant and a Northwestern University Dixon Translational Research Grant Initiative Award. HP was supported by NIH grant AR064546, HL134375, AG049665, UH2AR067687, the United States-Israel Binational Science Foundation (2013247), and the Rheumatology Research Foundation (Agmt 05/06/14). HP was also supported by the Mabel Greene Myers Professor of Medicine and generous donations to the Rheumatology Precision Medicine Fund. JAL was supported by NIH grant K08 EY030923. No funding body had any role in the design of the study, collection, analysis, interpretation of data, or in writing the manuscript.

\section{Availability of data and materials}

The datasets used and analyzed for mouse studies are available from the corresponding author on reasonable request. All human data analyzed during this study are included in this published article and its supplementary information files.

\section{Ethics approval}

All experiments were conducted in accordance with the ARVO Statement for the Use of Animals in Ophthalmic and Vision Research and were approved by the Northwestern University Institutional Animal Care and Use Committee.

\section{Consent for publication}

Not applicable.

\section{Competing interests}

The authors declare that they have no competing interests.

\section{Author details}

${ }^{1}$ Department of Ophthalmology, Feinberg School of Medicine, Northwestern University, 240 E Huron St, McGaw M343, Chicago, IL 60611, USA.

${ }^{2}$ Department of Medicine, Division of Nephrology and Hypertension, Feinberg Cardiovascular and Renal Research Institute, Feinberg School of Medicine, Northwestern University, Chicago, IL, USA. ${ }^{3}$ Department of Medicine, Division of Rheumatology, Feinberg School of Medicine, Northwestern University, Chicago, IL, USA.

Received: 17 August 2020 Accepted: 28 October 2020

Published online: 13 November 2020

\section{References}

1. Brown DM, Kaiser PK, Michels M, Soubrane G, Heier JS, Kim RY, et al. Ranibizumab versus verteporfin for neovascular age-related macular degeneration. N Engl J Med. 2006;355(14):1432-44.

2. CATT Research Group, Martin DF, Maguire MG, Ying G-S, Grunwald JE, Fine SL, et al. Ranibizumab and bevacizumab for neovascular age-related macular degeneration. N Engl J Med. 2011;364(20):1897-908. 
3. Klein RJ, Zeiss C, Chew EY, Tsai J-Y, Sackler RS, Haynes C, et al. Complement factor $\mathrm{H}$ polymorphism in age-related macular degeneration. Science. 2005; 308(5720):385-9.

4. Yates JRW, Sepp T, Matharu BK, Khan JC, Thurlby DA, Shahid H, et al. Complement C3 variant and the risk of age-related macular degeneration. N Engl J Med. 2007;357(6):553-61.

5. Edwards AO, Ritter R, Abel KJ, Manning A, Panhuysen C, Farrer LA. Complement factor $\mathrm{H}$ polymorphism and age-related macular degeneration. Science. 2005;308(5720):421-4.

6. Mullins RF, Russell SR, Anderson DH, Hageman GS. Drusen associated with aging and age-related macular degeneration contain proteins common to extracellular deposits associated with atherosclerosis, elastosis, amyloidosis, and dense deposit disease. FASEB J. 2000;14(7):835-46.

7. Nozaki M, Raisler BJ, Sakurai E, Sarma JV, Barnum SR, Lambris JD, et al. Drusen complement components C3a and C5a promote choroidal neovascularization. Proc Natl Acad Sci U S A. 2006;103(7):2328-33.

8. Nakamura R, Sene A, Santeford A, Gdoura A, Kubota S, Zapata N, et al. IL10driven STAT3 signalling in senescent macrophages promotes pathological eye angiogenesis. Nat Commun. 2015;6(1):7847.

9. Sakurai E, Anand A, Ambati BK, van Rooijen N, Ambati J. Macrophage depletion inhibits experimental choroidal neovascularization. Invest Ophthalmol Vis Sci. 2003;44(8):3578-85.

10. Yang X, Zhao L, Campos MM, Abu-Asab M, Ortolan D, Hotaling N, et al. CSF1R blockade induces macrophage ablation and results in mouse choroidal vascular atrophy and RPE disorganization. Elife. 2020;9:18.

11. Ginhoux F, Guilliams M. Tissue-resident macrophage ontogeny and homeostasis. Immunity. 2016:44(3):439-49.

12. Kierdorf K, Masuda T, Jordão MJC, Prinz M. Macrophages at CNS interfaces: ontogeny and function in health and disease. Nat Rev Neurosci. 2019;1:1-16.

13. O'Koren EG, Yu C, Klingeborn M, Wong AYW, Prigge CL, Mathew R, et al. Microglial function is distinct in different anatomical locations during retinal homeostasis and degeneration. Immunity. 2019;1:1-23.

14. Voigt AP, Mulfaul K, Mullin NK, Flamme-Wiese MJ, Giacalone JC, Stone EM, et al. Single-cell transcriptomics of the human retinal pigment epithelium and choroid in health and macular degeneration. Proc Natl Acad Sci U S A. 2019;116(48):24100-7.

15. Droho S, Cuda CM, Perlman H, Lavine JA. Monocyte-derived macrophages are necessary for beta-adrenergic receptor-driven choroidal neovascularization inhibition. Invest Ophthalmol Vis Sci. 2019;60(15):5059-69.

16. Droho S, Cuda CM, Lavine JA. Digestion of whole mouse eyes for multi-parameter flow cytometric analysis of mononuclear phagocytes. J Vis Exp. 2020;160:1-20.

17. Stuart T, Butler A, Hoffman P, Hafemeister C, Papalexi E, Mauck WM III, et al. Comprehensive integration of single-cell data. Cell. 2019;177(7):1888-1902.e21.

18. Butler A, Hoffman P, Smibert P, Papalexi E, Satija R. Integrating single-cell transcriptomic data across different conditions, technologies, and species. Nat Biotechnol. 2018;36(5):411-20.

19. Eden E, Navon R, Steinfeld I, Lipson D, Yakhini Z. GOrilla: a tool for discovery and visualization of enriched $\mathrm{GO}$ terms in ranked gene lists. BMC Bioinform. 2009;10(1):25-7.

20. Eden E, Lipson D, Yogev S, Yakhini Z. Discovering motifs in ranked lists of DNA sequences. Fraenkel E, editor. PLoS Comput Biol. 2007:3(3):e39-15.

21. Supek F, Bošnjak M, Škunca N, Šmuc T. REVIGO summarizes and visualizes long lists of gene ontology terms. Gibas C, editor. PLoS One. 2011;6(7):e21800-9.

22. O'Koren EG, Mathew $R$, Saban DR. Fate mapping reveals that microglia and recruited monocyte-derived macrophages are definitively distinguishable by phenotype in the retina. Nat Publ Group. 2016;1:1-12.

23. Tsutsumi $\mathrm{C}$. The critical role of ocular-infiltrating macrophages in the development of choroidal neovascularization. J Leukoc Biol. 2003;74(1):25-32.

24. Pennington $\mathrm{KL}$, DeAngelis MM. Epidemiology of age-related macular degeneration (AMD): associations with cardiovascular disease phenotypes and lipid factors. Eye Vis. 2016:1:1-20.

25. Rudnicka AR, Kapetanakis W, Jarrar Z, Wathern AK, Wormald R, Fletcher AE, et al. Incidence of late-stage age-related macular degeneration in American whites: systematic review and meta-analysis. AJOPHT. 2015;160(1):85-93.e3.

26. Yona S, Kim K-W, Wolf Y, Mildner A, Varol D, Breker M, et al. Fate mapping reveals origins and dynamics of monocytes and tissue macrophages under homeostasis. Immunity. 2013 Jan;38(1):79-91.

27. Di YU, Zhang Y, Nie Q, Chen X. CCN1/Cyr61-PI3K/AKT signaling promotes retinal neovascularization in oxygen-induced retinopathy. Int J Mol Med. 2015:36(6):1507-18.
28. Barnett JM, Suarez S, McCollum GW, Penn JS. Endoglin promotes angiogenesis in cell- and animal-based models of retinal neovascularization. Invest Ophthalmol Vis Sci. 2014;55(10):6490-8.

29. Yin X, Zhang B, Chen L, Xia W, Liu G, Zhu X, et al. Essential contribution of macrophage Tie2 signalling in a murine model of laser-induced choroidal neovascularization. Sci Rep. 2020;10:1-11.

30. Coroniti R, Fario R, Nuno DJ, Otvos L, Scolaro L, Surmacz E. Designer leptin receptor antagonist Allo-aca inhibits VEGF effects in ophthalmic neoangiogenesis models. Front Mol Biosci Frontiers. 2016;3:648239-10.

31. Wojnarowicz PM, Silva RLE, Ohnaka M, Lee SB, Chin Y, Kulukian A, et al. A small-molecule pan-id antagonist inhibits pathologic ocular neovascularization. Cell Rep. 2019;29(1):62-7.

32. DeNiro M, Alsmadi O, Al-Mohanna F. Modulating the hypoxia-inducible factor signaling pathway as a therapeutic modality to regulate retinal angiogenesis. Exp Eye Res. 2009;89(5):700-17.

33. Mathsyaraja H, Thies K, Taffany DA, Deighan C, Liu T, Yu L, et al. CSF1-ETS2induced microRNA in myeloid cells promote metastatic tumor growth. Oncogene. 2019;34:1-11.

34. Qi JH, Ebrahem Q, Moore N, Murphy G, Claesson-Welsh L, Bond M, et al. A novel function for tissue inhibitor of metalloproteinases-3 (TIMP3): inhibition of angiogenesis by blockage of VEGF binding to VEGF receptor-2. Nat Med. 2003:9(4):407-15.

35. Shi X, Semkova I, Müther PS, Dell S, Kociok N, Joussen AM. Inhibition of TNF-a reduces laser-induced choroidal neovascularization. Exp Eye Res. 2006;83(6):1325-34.

36. Dong A, Seidel C, Snell D, Ekawardhani S, Ahlskog JK, Baumann M, et al. Antagonism of PDGF-BB suppresses subretinal neovascularization and enhances the effects of blocking VEGF-A. Angiogenesis. 2014;17(3):553-62.

37. Silva RLE, Shen J, Hackett SF, Kachi S, Akiyama H, Kiuchi K, et al. The SDF-1/ CXCR4 ligand/receptor pair is an important contributor to several types of ocular neovascularization. FASEB J. 2007:21(12):3219-30.

38. Farnoodian M, Wang S, Dietz J, Nickells RW, Sorenson CM, Sheibani N. Negative regulators of angiogenesis: important targets for treatment of exudative AMD. Clin Sci. 2017;131(15):1763-80

39. Krause TA, Alex AF, Engel DR, Kurts C, Eter N. VEGF-production by CCR2dependent macrophages contributes to laser-induced choroidal neovascularization. Waisman a, editor. PLoS One. 2014:9(4):e94313-9.

40. Brockmann C, Kociok N, Dege S, Davids A-M, Brockmann T, Miller KR, et al. Local partial depletion of CD11b +cells and their influence on choroidal neovascularization using the CD11b-HSVTK mouse model. Acta Ophthalmol. 2018;96(7):e789-96.

41. Misharin AV, Cuda CM, Saber R, Turner JD, Gierut AK, Haines GK III, et al. Nonclassical Ly6C-monocytes drive the development of inflammatory arthritis in mice. Cell Rep. 2014;9(2):591-604.

42. Chinnery HR, McMenamin PG, Dando SJ. Macrophage physiology in the eye. Pflugers Arch. 2017:469(3-4):501-15.

43. Jakubzick C, Gautier EL, Gibbings SL, Sojka DK, Schlitzer A, Johnson TE, et al. Minimal differentiation of classical monocytes as they survey steady-state tissues and transport antigen to lymph nodes. Immunity. 2013;39(3):599-610.

44. Erdei A, Lukácsi S, Mácsik-Valent B, Nagy-Baló Z, Kurucz I, Bajtay Z. Nonidentical twins: different faces of CR3 and CR4 in myeloid and lymphoid cells of mice and men. Semin Cell Dev Biol. 2019;85:110-21.

45. Schittenhelm L, Hilkens CM, Morrison VL. $\beta 2$ Integrins as regulators of dendritic cell, monocyte, and macrophage function. Front Immunol Front. 2017;8:544-11.

46. Svoboda E, Schneider AE, Sándor N, Lermann U, Staib P, Kremlitzka M, et al. Secreted aspartic protease 2 of Candida albicans inactivates factor $\mathrm{H}$ and the macrophage factor H-receptors CR3 (CD11b/CD18) and CR4 (CD11C) CD18). Immunol Lett. 2015;168(1):13-21.

47. Lukácsi S, Nagy-Baló Z, Erdei A, Sándor N, Bajtay Z. The role of CR3 (CD11b/CD18) and CR4 (CD11c/CD18) in complement-mediated phagocytosis and podosome formation by human phagocytes. Immunol Lett. 2017 Sep;189:64-72.

48. Tan X, Fujiu K, Manabe I, Nishida J, Yamagishi R, Terashima Y, et al. Choroidal neovascularization is inhibited in splenic-denervated or splenectomized mice with a concomitant decrease in intraocular macrophage. Abe T, editor. PLoS One. 2016;11(8):e0160985.

49. Zhao X-F, Alam MM, Liao Y, Huang T, Mathur R, Zhu X, et al. Targeting microglia using Cx3cr1-Cre lines: revisiting the specificity. eNeuro. Soc Neurosci. 2019;6(4):1.

\section{Publisher's Note}

Springer Nature remains neutral with regard to jurisdictional claims in published maps and institutional affiliations. 